\title{
Neighborhood deprivation, vehicle ownership, and potential spatial access to a variety of fruits and vegetables in a large rural area in Texas
}

\author{
Joseph R Sharkey ${ }^{1,2 *}$, Scott Horel ${ }^{3}$, Wesley R Dean ${ }^{1,2}$
}

\begin{abstract}
Objective: There has been limited study of all types of food stores, such as traditional (supercenters, supermarkets, and grocery stores), convenience stores, and non-traditional (dollar stores, mass merchandisers, and pharmacies) as potential opportunities for purchase of fresh and processed (canned and frozen) fruits and vegetables, especially in small-town or rural areas.
\end{abstract}

Methods: Data from the Brazos Valley Food Environment Project (BVFEP) are combined with 2000 U.S. Census data for 101 Census block groups (CBG) to examine neighborhood access to fruits and vegetables. BVFEP data included identification and geocoding of all food stores $(n=185)$ in six rural counties in Texas, using ground-truthed methods and on-site assessment of the availability and variety of fresh and processed fruits and vegetables in all food stores. Access from the population-weighted centroid of each CBG was measured using proximity (minimum network distance) and coverage (number of shopping opportunities) for a good selection of fresh and processed fruits and vegetables. Neighborhood inequalities (deprivation and vehicle ownership) and spatial access for fruits and vegetables were examined using Wilcoxon matched-pairs signed-rank test and multivariate regression models.

Results: The variety of fruits or vegetables was greater at supermarkets compared with grocery stores. Among non-traditional and convenience food stores, the largest variety was found at dollar stores. On average, rural neighborhoods were 9.9 miles to the nearest supermarket, 6.7 miles and 7.4 miles to the nearest food store with a good variety of fresh fruits and vegetables, respectively, and 4.7 miles and 4.5 miles to a good variety of fresh and processed fruits or vegetables. High deprivation or low vehicle ownership neighborhoods had better spatial access to a good variety of fruits and vegetables, both in the distance to the nearest source and in the number of shopping opportunities.

Conclusion: Supermarkets and grocery stores are no longer the only shopping opportunities for fruits or vegetables. The inclusion of data on availability of fresh or processed fruits or vegetables in the measurements provides robust meaning to the concept of potential access in this large rural area.

\section{Introduction}

Adequate consumption of nutritious foods, such as fruits and vegetables, is essential for overall good nutritional health, and the prevention and management of nutrition-related health conditions, such as obesity, diabetes, cardiovascular disease, and some cancers [1-8]. Rural populations face some of the same challenges as urban or suburban counterparts but often at a higher

\footnotetext{
* Correspondence: jrsharkey@srph.tamhsc.edu

${ }^{1}$ Program for Research in Nutrition and Health Disparities, School of Rural Public Health, Texas A\&M Health Science Center, MS 1266, College Station, TX 77843-1266 USA
}

(C) 2010 Sharkey et al; licensee BioMed Central Ltd. This is an Open Access article distributed under the terms of the Creative Commons Attribution License (http://creativecommons.org/licenses/by/2.0), which permits unrestricted use, distribution, and reproduction in any medium, provided the original work is properly cited. degree of severity [9]. Both rural men and women have higher rates of self-reported obesity than men and women in other areas; and rural minorities face an added burden of health risk behaviors based on rural residence and race- and ethnicity-related health disparities [10]. Results from the 1999-2000 National Health and Nutrition Examination Survey (NHANES) indicate that a large proportion of American children and adults do not meet the recommendations for fruit and vegetable intake [11]. Additional studies found low fruit and vegetable consumption among rural populations, especially among low-income and minority subgroups 
$[12,13]$. Although the consumption of fruits and vegetables is recommended, they are often not easily accessible [14-16], especially in small-town and rural areas which also lack transportation infrastructure [17]. Consequently, ecological approaches to behavior change and health recognize that there is a dynamic interaction between the individual and where they live [18-21].

Various social-ecological frameworks have been used to explain the influence of environment - physical, social, and economic - on individual behaviors $[18,19,22,23]$. Specifically, social-ecological approaches to food choice and healthful eating recognized that access to food stores may have an effect upon health and well-being, as well as adherence to dietary recommendations [24-27]. The conceptual model in Figure 1, which is based on work in access to healthcare $[28,29]$ provides a framework for understanding food access. This model shows access to healthful food is the result of the relationship between the retail food environment and potential consumers, and suggests food choice and healthful eating are influenced by available (potential access) and utilized (realized access) shopping opportunities. Characteristics of the food environment include: number, type, size, and location of food stores; availability (supply) of food categories (e.g., fresh fruits); and variety of different items within a category (e.g., different types of fresh fruits); price and quality of food items. Characteristics of potential consumers include neighborhood of residence, availability of a vehicle, public transportation, financial resources (type, amount, and timing), home environment (food storage, meal preparation area, and refrigeration), food preferences, meal preparation knowledge and skills, household size, employment, culture, and health. Barriers or facilitators associated with the food environment and/or consumer influence the selection of food purchase opportunity at a given time. For example, limited household refrigeration may require frequent, costly trips for perishable food items; or purchase of more expensive or less healthy food items from a retail store closer to home $[14,30,31]$. As a result, proximity to food stores may influence food choice through food cost and availability $[24,25,27,32,33]$.

Research on geographic or spatial access from the home to food stores describes a more recent and growing approach to understand access to a variety of healthy foods and to eliminate inequalities in nutritionrelated health conditions $[20,34,35]$. There are various measures that have been used to describe different dimensions of accessibility to food stores. The approach most prevalent in the literature is a measure of proximity or distance (straight-line or network) to the nearest food store [17,36-39]. Other dimensions include coverage (number of food stores within a specified distance or buffer area) [27,37], variety (average distance to the three closest different chain-name supermarkets) [37], and density (proportion or ratio of food stores per county, Census tract, or Census block group) $[24,25]$.

U.S. studies have documented better-quality diets for individuals who reside in closer proximity of supermarkets [40,41]; better access and availability of produce was associated with greater intake of fruits and vegetables $[24,33,42-44]$. However, physical access may be a major problem for people in deprived or rural communities, especially those without cars, the elderly, and people on low incomes [41,45-49]. In contrast to these studies, research in the U.K. found no association between distances to the nearest supermarket and fruit or vegetable consumption [50], or inconsistent results between the introduction of a new supermarket and consumption [51,52].

There is strong evidence that residents of small-town and rural areas are affected by poor access to supermarkets and healthy food items [17,36,53-58]. In the only U.S. study of neighborhood deprivation and proximity to food stores in a rural area, investigators found that more socioeconomically-deprived neighborhoods (defined by Census block group) had relatively better potential access to retail food stores compared with other neighborhoods [36]. The distance to the nearest supermarket was still beyond usual walking distance.

The preponderance of published work on food access focused on supermarkets and occasionally grocery stores [17,37-40,49,56,59-61]. This limited focus ignores changing market factors that extend beyond supermarkets [34]. The "true" availability of healthy foods may be underestimated, since some of these foods may be available in convenience and non-traditional food stores $[17,58]$. Traditional food stores, such as supermarkets and grocery stores, are facing increased competition from supercenters, convenience stores, and non-traditional food stores $[62,63]$. Non-traditional formats, such as drug stores, mass merchandisers, and dollar stores, have perfected "channel blurring" with the rapid expansion of food items to their customary non-food format $[64,65]$. Over the past 10 years, non-traditional food stores have increased the variety of shopping and food options with the introduction of refrigerated and frozen sections to their stores and lower food prices to consumers, all at the expense of traditional supermarkets and grocery stores [63-65]. While the opportunities for lower priced food items, especially for low-income families, have multiplied, these increased opportunities do not necessarily provide improved opportunities for healthier alternatives [58]. Rural areas are most affected by these changing market forces, where distance and transportation become even more of a factor [17,66-68]. 


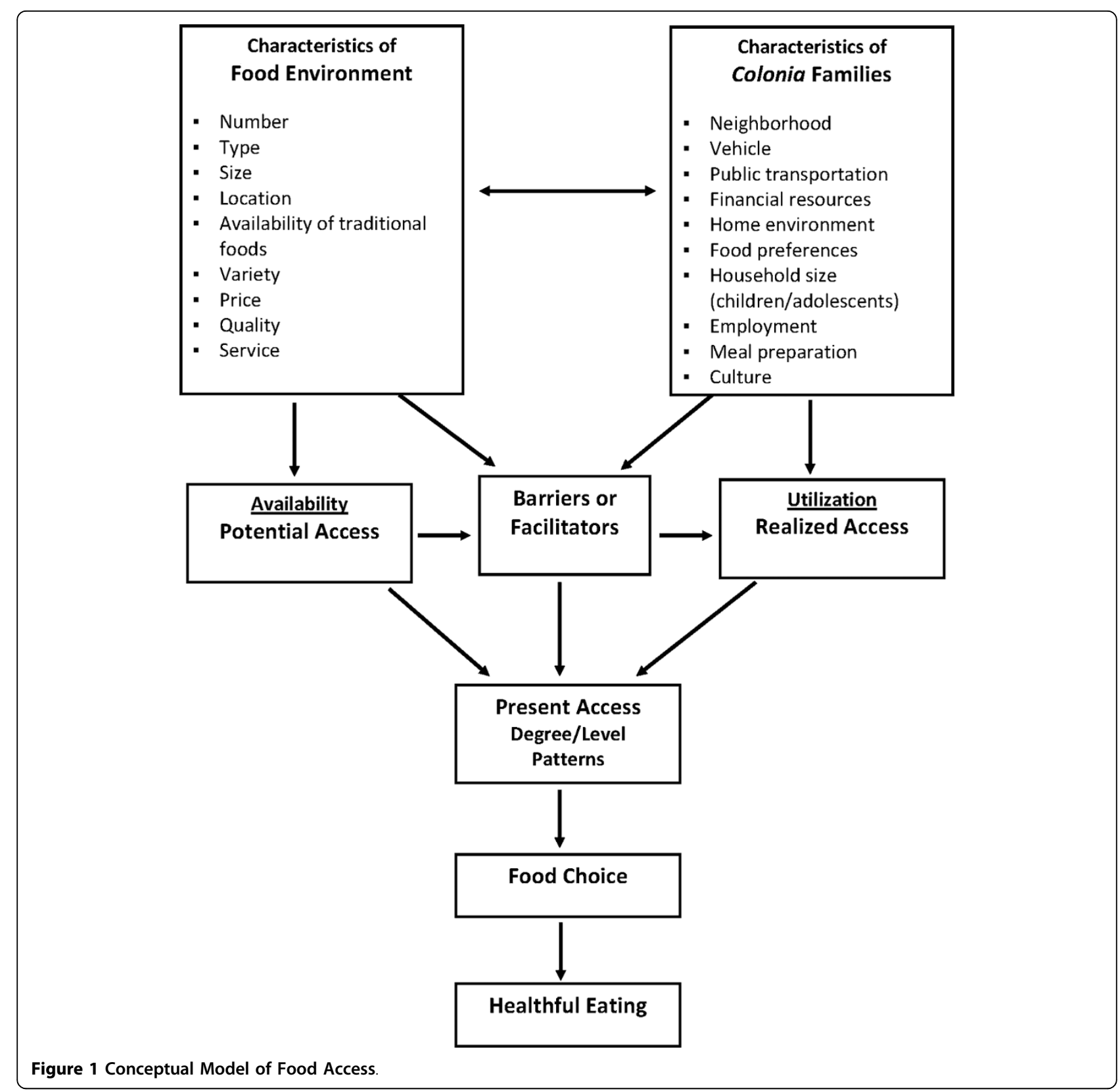

In a broader sense, accessibility could be defined as potential access to healthier foods, with availability (food items present and ready for purchase) having a greater influence on food choice and consumption [69]. Little is known about the influence of changing market factors, such as the expansion of food offerings by mass merchandisers and dollar stores, on access to and availability of healthy foods, especially in rural areas. The U.S. Department of Agriculture's food guidance system in its dietary recommendations for fruits and vegetables identify canned, frozen, and $100 \%$ juice in addition to fresh as a way to help people achieve the recommended variety and amount of fruits and vegetables [70]. Studies, for the most part, have limited their investigations to the availability of fresh fruits and vegetables, which ignore the nutrient benefits of canned and frozen fruits and vegetables [71-75]. In a comprehensive review of fresh, frozen, and canned fruits and vegetables, Rickman and colleagues reported that freezing and canning processes may preserve nutrient value that may be lost in fresh products during storage and cooking [74]. In a 1997 study, Klein and Kaletz found that canned and frozen fruits and vegetables are at least nutritionally comparable to fresh [69]. They further confirmed that canned foods may be sometimes better than fresh and frozen varieties in their nutritional contribution to the 
diet. In addition, all canned fruits and fruit juices contribute less than two percent of added sugars in most American's diet and vegetables contribute less than one percent of sodium [76,77].

Nutritional and health disparities faced by low-income families in small-town and rural areas throughout the world make understanding the effects of changing market factors on access to a variety of fruits and vegetables especially critical $[78,79]$. This study expands our understanding, both within the United States and internationally, of potential spatial access to a variety of fruits and vegetables by small-town and rural residents by 1) describing the availability (supply) of fresh and processed fruits and vegetables in traditional, convenience, and non-traditional food stores; 2) determining network-based potential access to fresh and processed fruits and vegetables using proximity and coverage criteria for access; and 3) examining the relationship of between neighborhood inequalities (e.g., socioeconomic deprivation and vehicle ownership) and potential access to fresh and processed fruits and vegetables. This is important, considering that $14 \%$ of Supplemental Nutrition Assistance Program (SNAP) benefits were not redeemed at supermarkets or large grocery stores and were used to purchase less noncanned fruits or vegetables [17]. Further, the inclusion of fresh and processed fruits and vegetables from all traditional, convenience, and nontraditional food stores is applicable for an international audience that is concerned with geographic inequities in access to a variety of healthy foods.

\section{Methods \\ Geographic setting}

The study used data from the 2006-2007 Brazos Valley Food Environment Project (BVFEP), which was approved by the Institutional Review Board at Texas A\&M University, and the decennial 2000 U.S. Census Summary File 3 (SF-3) for six rural counties in the Central Texas Brazos Valley region (see Figure 2). The BVFEP has a history of working with community partners in the seven-county Brazos Valley region of Texas (one urban and six rural counties); all six rural counties were included in this study. These counties, which consist of 101 Census block groups (CBGs) and include five urban clusters (population $>2,500$ ), are considered rural based on population density [80,81]. The rural region covered a land area of $4,466 \mathrm{~m}^{2}$ and included a population of 119,654 people [82]. According to the 2000 U.S. Census at the area-level of CBG, the median proportion of minority resident was $24.6 \%$ (range $3.6 \%-89.8 \%$ ); unemployment was $2.4 \%$ (range $0 \%-8.8 \%$ ); median of $37.9 \%$ of households (range $0 \%-72.8 \%$ ) reported an income under $200 \%$ federal poverty level (FPL); a median of $14.2 \%$ (range $0 \%-39.8 \%$ ) completed less than nine years of education; $49.4 \%$ (range $0 \%-71.8 \%$ ) of housing owner-occupied; median income of $\$ 32,269$ (range $\$ 8235-\$ 51,776$ ), and 37\% (range 0\%-74.8\%) travel at least 30 minutes to work [83]. More than $41 \%$ of the $101 \mathrm{CBG}$ are considered low-income areas; that is, areas in which at least $40 \%$ of residents has income at or below 200\% FPL [17]. Regular public transportation services, such as fixed route, commuter, or taxi services, were not available in the study area $[84,85]$.

\section{Neighborhood (area-level) inequalities}

The CBG, which is the smallest unit of Census geography for which the detailed "long-form" social and economic data from the Census are tabulated, was selected to define a neighborhood $[36,86]$. Neighborhood social and material deprivation. We applied the Neighborhood Socioeconomic Deprivation Index to each of the 101 CBG in the rural study area [36]. This measure of compound social and material deprivation was calculated from the 2000 U.S. Census Summary File 3 (SF-3) and included unemployment (persons age 16 years and older in the labor force who were unemployed and actively seeking work), poverty (persons with incomes below the federal poverty level), low education attainment (persons age 25 years and older, with less than a $10^{\text {th }}$-grade education), household crowding (occupied households with more than one person per room), public assistance (households receiving public assistance), vehicle availability (occupied housing with no vehicle available), and telephone service (occupied housing with no telephone service). Based on the distribution of scores for the index, a three-category variable for overall neighborhood socioeconomic deprivation was constructed and assigned to each CBG: low deprivation (highest overall socioeconomics and lowest quartile of deprivation scores), middle deprivation (middle two quartiles), and high deprivation (lowest overall socioeconomics and highest quartile of deprivation scores) [36]. Vehicle ownership. Data from SF-3 were used to determine CBG-level vehicle ownership (occupied housing with vehicle available). Tertiles were used to construct a three-category variable for vehicle ownership (range of $62 \%$ to $100 \%$ ); $<90.5 \%$ of households with a vehicle was considered low ownership, $90.5 \%$ to $95.4 \%$ medium, and $>95.4 \%$ high vehicle ownership.

\section{Food store data}

In the 2006 Brazos Valley Health Assessment, random digit dialing methodology was used to recruit adults from the six rural counties in this study for a mailed survey [Wendel, Alaniz, Burdine, Sharkey, Felix, Windwehen: Regional Efforts Aimed at Health Equity: A Case Study in the Brazos Valley, submitted]. More than 1,400 participants responded to a question that asked in what 


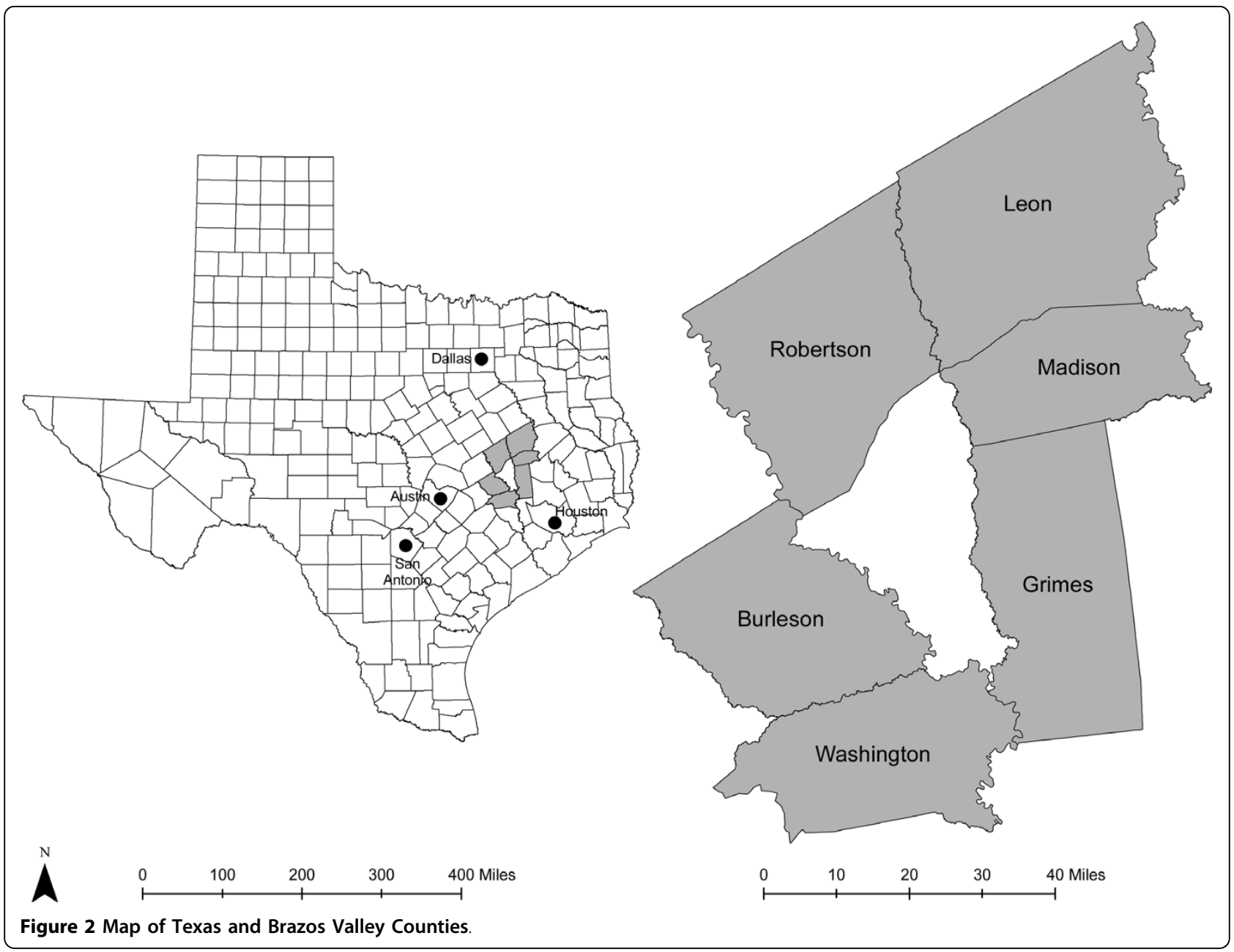

type of store they buy most of their groceries. Almost $80 \%$ identified a supermarket or warehouse store; $15.9 \%$ a small grocery store; and $4.8 \%$ identified a convenience store or other. The BVFEP used ground-truthed methods in a two-stage approach to determine the access to and availability of fruits and vegetables to residents of the $101 \mathrm{CBG}$. In the first stage, trained observers systematically drove all highways (Interstate, U.S., and State), farm-to-market roads, and city or town streets/ roads within the study area. All traditional (supercenters, supermarkets, and grocery stores), convenience (convenience stores and food marts), and non-traditional (dollar stores, mass merchandisers, and pharmacies) food stores were enumerated through direct observation and on-site determination of geographic coordinates using a Bluetooth Wide Area Augmentation System (WAAS)-enabled portable Global Positioning System (GPS) receiver and the World Geodetic System 1984 datum $[34,36]$. In the second stage, an observational survey instrument was developed, tested, and administered in all food stores by trained observers to determine the availability and variety of fruits and vegetables [58]. Definitions used to classify specific types of food stores are shown in Table 1.

\section{Measurement of fruits and vegetable availability}

The availability of fruits and vegetables was separately determined from the presence and variety of fresh and processed fruits and vegetables $[30,58]$. Processed fruits and vegetables included healthier canned, frozen, and juice [74]. Healthier forms of processed fruits included fruits canned in natural juice, fruits canned in light syrup, frozen fruits without added sugar, and 100\% fruit juice. Healthier forms of processed vegetables included vegetables canned or frozen without oil or a sauce and $100 \%$ vegetable juice. Variety was operationalized as the number of different food items within a fruit or vegetable category (e.g., number of different fresh fruits or number of different types of canned fruits in natural juice). 


\section{Table 1 Definition of types of food stores used in this study}

\begin{tabular}{|c|c|}
\hline $\begin{array}{l}\text { Supercenters or } \\
\text { superstores }\end{array}$ & $\begin{array}{l}\text { Very large stores that primarily engage in retailing a general line of groceries in combination with general lines of } \\
\text { new merchandise, such as apparel, furniture, and appliances (e.g., Super Wal-Mart, Super Kmart). }\end{array}$ \\
\hline Supermarkets & $\begin{array}{l}\text { Primarily engage in retailing a general line of food, supermarkets are larger in size }(>20,000 \mathrm{sq} f \mathrm{ft}) \text {, number of } \\
\text { employees, and sales volume [98]. Chain store identification and number of parking spaces }(>100) \text { were used to } \\
\text { distinguish supermarkets from grocery stores }[65,108] \text {. }\end{array}$ \\
\hline Grocery stores & $\begin{array}{l}\text { Primarily engage in retailing a general line of food, grocery stores are smaller in size, not identified as a chain store } \\
\text { and have fewer than } 100 \text { parking spaces. }\end{array}$ \\
\hline $\begin{array}{l}\text { Convenience stores or } \\
\text { food marts }\end{array}$ & $\begin{array}{l}\text { Primarily engage in retailing a limited line of goods that generally includes milk, bread, soda, and snacks. The } \\
\text { convenience store category also included convenience stores with gasoline and gasoline stations with convenience } \\
\text { stores. }\end{array}$ \\
\hline Mass merchandisers & Large, general merchandise "value" stores, such as Kmart, Target, and Wal-Mart. \\
\hline Dollar stores & Limited-price general merchandise "value" stores, such as Dollar General or Family Dollar $[65,93]$. \\
\hline $\begin{array}{l}\text { Pharmacies and drug } \\
\text { stores }\end{array}$ & Pharmacies and drug stores that were part of national chains (e.g., CVS, Walgreens). \\
\hline
\end{tabular}

\section{Overall fruit score}

Separate scores were constructed to reflect a total of different types of fresh fruits $(0=$ none, $1=1-4$, and $2=\geq 5)$; canned fruits in natural juice $(0=$ none, $1=1-4$, and $2=$ $\geq 5)$; canned fruits in light syrup ( $0=$ none, $1=1-4$, and $2=\geq 5)$; frozen fruits $(0=$ none, $1=1-4$, and $2=\geq 5)$; and $100 \%$ fruit juice ( $0=$ none, $1=$ any). A summary score for overall fruits was created by summing the category scores for the number of varieties of fresh fruits, canned fruits in natural juice, canned fruits in light syrup, frozen fruits, and $100 \%$ fruit juice. Overall fruit scores range from 0 (worst availability of fruits) to 9 (best availability of fruits). Because the overall fruits score was highly skewed, a three-category variable was constructed for level of overall fruits availability: poor availability (lowest tertile; fruits score 0-1), medium availability (second tertile; fruits score 2-3), and good availability (highest tertile; fruits score 4-9).

\section{Overall vegetable score}

The overall vegetable availability score combines variety and the presence of a dark green vegetable (e.g., broccoli, collard greens, kale, spinach, or turnip greens) [70]. Separate scores were constructed from a total of different fresh vegetables $(0=$ none, $1=1-4$ and no dark green vegetable, $2=\geq 5$ and no dark green vegetable or 1-4 and a dark green vegetable, $3=\geq 5$ and a dark green vegetable); canned vegetables ( $0=$ none, $1=1-4$ and no dark green vegetable, $2=\geq 5$ and no dark green vegetable or 1-4 and a dark green vegetable, $3=\geq 5$ and a dark green vegetable); frozen vegetables $(0=$ none, $1=1-4$, and $2=\geq 5)$; and $100 \%$ vegetable juice ( $0=$ none, 1 = any). Overall vegetable scores range from 0 (worst availability of vegetables) to 10 (best availability of vegetables). A three-category variable was constructed for level of overall vegetable availability: poor availability (vegetable score: $0-1$ ), medium availability (vegetable score: 2-3), and good availability (vegetable score: 4-10).

\section{Potential Spatial Access}

The population-weighted centroid, which is a more accurate measure than the geographic centroid [36], for each of the 101 CBG was calculated using the ArcGIS Desktop tool Mean Center (Version 9.2, Environmental Systems Research Institute). This tool constructs the CBG mean center based on the mean-weighted $x$ and $y$ values of the block population centroids [36]. Two criteria of potential spatial access were calculated from each CBG [36,87]: 1) proximity, and 2) coverage [37]. Proximity was chosen since it is typically used to measure distance to the nearest food store. Coverage adds the dimension of variety and competition within a specific distance and is not limited to the food stores within an administratively-defined area, such as CBG or Census tract. Proximity: ESRI's Network Analyst extension in ArcInfo 9.2 was used to calculate the shortest network distance along the road network between two sets of paired point data: neighborhood (population-weighted CBG centroid) and the nearest corresponding food store within the six-county study area. The 2003 Tele Atlas Dynamap Transportation version 5.2 provided network data. Separate distances were calculated from each CBG to the nearest supercenter, supermarket, grocery store, convenience store, mass merchandiser, dollar store, and pharmacy in miles. Coverage: Network Analyst computed the total number of each type of food store within one, three, five, and 10 miles, using the shortest network distance from the populationweighted center of each CBG. Since the study area is not a large, highly dense urban area as much of the limited literature describes (e.g., Chicago, Detroit, Montreal, Los Angeles) $[32,37,38]$, coverage distances were selected that represented a long walk (1 mile) and reachable by car (within 3, 5, and 10 miles). Proximity measured the shortest distance needed to travel to a specific type of food store, while coverage indicates the number of opportunities. More opportunities equates to greater accessibility [88]. Proximity and coverage measures were calculated for all traditional, convenience, and non-traditional food stores with a good selection of fresh fruits or vegetables, and food stores with a good selection of fresh or processed fruits or vegetables. 


\section{Statistical analysis}

Release 11 of Stata Statistical Software was used for all statistical analyses; $p<0.05$ was considered statistically significant. Descriptive statistics were estimated for availability of fresh and processed fruits and vegetables by type of food store. Nonparametric tests for trend were estimated across categories of increasing neighborhood deprivation [89]. Distances from the population-weighted centroid of each CBG to the nearest supermarket, traditional food store (supercenter, supermarket, or grocery store), convenience store, and non-traditional (dollar store, mass merchandiser, and pharmacy) food store were calculated. Distance to the nearest supermarket was compared with the distance to the nearest food store with a good variety of fresh fruits, fresh vegetables, fresh and processed fruits, or fresh and processed vegetables by testing for equalities in mean, median, and distribution of distance measures, using Wilcoxon Matched-Pairs signed-rank test. This is a nonparametric test to determine differences between groups of paired data. The null hypothesis is that there is no difference between both distributions. Finally, three multivariate regression models were fitted to determine the relationship of neighborhood deprivation or vehicle ownership to potential spatial access to a good variety of fruits and vegetables, controlling for population density: 1) proximity, 2) 3-mile coverage, and 3) 5-mile coverage. In multivariate regression, several dependent variables are jointly regressed on the same independent variables. The multivariate model approach was chosen instead of four separate multiple regression models (one for each outcome variable) for two reasons: 1) the four outcome variables are correlated with each other and the multivariate regression accounts for this correlation when testing hypotheses about the predictor variables; and 2) the final collection of models is easier to interpret if the same predictor variables are identified.

\section{Results}

\section{Neighborhood characteristics and food stores}

Table 2 shows the distribution of neighborhood socioeconomic characteristics and high levels of neighborhood need in the study area, which are presented as mean and standard deviation for the overall study area and by area-level (CBG) deprivation. There were $26 \mathrm{CBG}$ $(25.7 \%)$ in the five urban clusters (population range $3,181$ to 11,952$)$; $61.5 \%(n=16)$ were considered high deprivation neighborhoods; and $81.8 \%$ of supermarkets $(n=9)$ were located in five urban clusters [36]. The percent of all socioeconomic characteristics increased significantly with increasing levels of deprivation. Table 2 also shows the distribution of proximity and coverage measures to supermarkets, traditional, convenience, and non-traditional food stores. Access to the nearest food store and the number of the food stores improves with increasing deprivation. Table 3 shows characteristics of CBG that are at least 10 miles one-way from the nearest supermarket or traditional food store. Residents in $47.5 \%$ of the 101 neighborhoods (CBG) and $39.3 \%$ of rural residents had to travel at least 10 miles; $26.7 \%$ of CBG and $20.7 \%$ of the population were at least 15 miles from a supermarket; and $12.9 \%$ of $C B G$ and $10.5 \%$ of population were at least 20 miles from a supermarket. More than $40 \%$ of low-income CBG were at least 10 miles from nearest supermarket.

\section{Availability of fruits and vegetables}

Observational surveys were completed in 185 (99.5\%) food stores; one convenience store refused to participate. Table 4 shows the availability and variety of fresh and processed fruits and vegetables by food store type. As a group, convenience stores provided less availability of fruits and vegetables than traditional or non-traditional food stores. Almost 100\% of non-traditional food stores (i.e., dollar stores, mass merchandisers, and pharmacies) offered processed fruits and vegetables. A greater percentage of convenience stores offered processed vegetables rather than processed fruits. The data show that variety of fresh or processed fruits and vegetables was better in supermarkets compared with grocery stores, and in dollar stores compared with convenience stores. Summary scores for availability and variety of fruits and vegetables, which combine fresh and processed fruits or vegetables show that dollar stores offered a greater variety of fruits than either convenience stores or mass merchandisers; variety of vegetables was greater at supermarkets compared with grocery stores. Table 5 shows the level of availability and variety of fruits and vegetables, based on a summary score of the number of different types of fruits or vegetables present. All traditional food stores marketed a good variety fruits and vegetables. More than $43 \%$ of dollar stores and $10 \%$ of convenience stores offered a good variety of fruits and almost $94 \%$ of dollar stores and $28 \%$ of convenience stores displayed a good variety of vegetables.

\section{Potential spatial access to fruits and vegetables}

As shown in Table 6, access was best for high deprivation neighborhoods - in proximity and in the number of shopping opportunities. Overall, residents had to travel a shorter distance for a good variety of fresh fruits, fresh vegetables, fresh and processed fruits, or fresh and processed vegetables than to the nearest supermarket. The difference in distance to the nearest supermarket compared with the nearest food store with a good selection of fruits or vegetables remained significant for low and medium economically deprived neighborhoods; however, the differences were not statistically significant for high 
Table 2 Neighborhoods characteristics and spatial accessibility to traditional, convenience, and non-traditional food stores by neighborhood socioeconomic deprivation, using measures of proximity and coverage*

\begin{tabular}{|c|c|c|c|c|}
\hline & $\begin{array}{l}\text { All Deprivation } \\
(n=101)\end{array}$ & $\begin{array}{l}\text { Low Deprivation } \\
\quad(n=26)\end{array}$ & $\begin{array}{c}\text { Medium Deprivation } \\
(n=48)\end{array}$ & $\begin{array}{l}\text { High Deprivation } \\
\quad(n=27)\end{array}$ \\
\hline \multicolumn{5}{|l|}{ Socioeconomic characteristics $^{\dagger}$} \\
\hline Unemployment,\% & $2.8 \pm 1.9$ & $2.3 \pm 1.5$ & $2.7 \pm 1.8$ & $3.5 \pm 2.1^{\ddagger}$ \\
\hline Income $<100 \%$ FPL, $\%$ & $16.0 \pm 9.6$ & $10.0 \pm 4.4$ & $13.3 \pm 4.6$ & $26.5 \pm 11.5^{\natural}$ \\
\hline Low education, $\%$ & $15.2 \pm 7.2$ & $9.9 \pm 3.7$ & $15.0 \pm 5.7$ & $20.6 \pm 8.2^{\pi}$ \\
\hline Crowded households, $\%$ & $5.7 \pm 5.1$ & $3.2 \pm 2.7$ & $4.8 \pm 3.8$ & $9.8 \pm 6.3^{9}$ \\
\hline Public assistance, $\%$ & $2.9 \pm 3.0$ & $1.5 \pm 1.8$ & $2.8 \pm 2.8$ & $4.7 \pm 3.7^{\natural}$ \\
\hline No vehicle available, $\%$ & $8.9 \pm 7.9$ & $3.7 \pm 2.7$ & $6.8 \pm 3.9$ & $17.5 \pm 9.9$ \\
\hline No telephone service, $\%$ & $4.9 \pm 3.9$ & $3.2 \pm 2.4$ & $4.4 \pm 3.0$ & $7.4 \pm 5.1^{\natural}$ \\
\hline Population density & $353.7 \pm 755$ & $153.5 \pm 672.6$ & $235.8 \pm 613.4$ & $756 \pm 918^{q}$ \\
\hline \multicolumn{5}{|l|}{ SPATIAL ACCESSIBILITY } \\
\hline \multicolumn{5}{|l|}{ Proximity, mi } \\
\hline Supermarket & $9.9 \pm 8.5$ & $11.4 \pm 8.8$ & $12.1 \pm 8.0$ & $4.7 \pm 6.8^{\ddagger}$ \\
\hline Traditional food store & $7.0 \pm 6.3$ & $9.4 \pm 6.8$ & $8.2 \pm 5.8$ & $2.5 \pm 4.3^{\ddagger}$ \\
\hline Convenience store & $3.1 \pm 2.5$ & $3.7 \pm 2.7$ & $3.8 \pm 2.3$ & $1.2 \pm 2.0^{\ddagger}$ \\
\hline Non-traditional food store ${ }^{* *}$ & $8.0 \pm 6.5$ & $9.5 \pm 6.8$ & $9.2 \pm 6.0$ & $4.3 \pm 6.0^{\S}$ \\
\hline \multicolumn{5}{|l|}{ Coverage - $1 \mathrm{mi}$} \\
\hline Supermarket & $0.32 \pm 0.58$ & $0.23 \pm 0.59$ & $0.12 \pm 0.39$ & $0.74 \pm 0.66^{\ddagger}$ \\
\hline Traditional food stores ${ }^{\#}$ & $0.45 \pm 0.75$ & $0.27 \pm 0.67$ & $0.25 \pm 0.70$ & $1.0 \pm 0.68^{\ddagger}$ \\
\hline Convenience stores & $1.9 \pm 2.9$ & $1.3 \pm 2.8$ & $0.79 \pm 1.8$ & $4.5 \pm 3.0^{\ddagger}$ \\
\hline Non-traditional food store ${ }^{* *}$ & $0.55 \pm 1.0$ & $0.58 \pm 1.4$ & $0.27 \pm 0.71$ & $1.0 \pm 1.0^{\S}$ \\
\hline \multicolumn{5}{|l|}{ Coverage - $3 \mathrm{mi}$} \\
\hline Supermarket & $0.67 \pm 1.0$ & $0.58 \pm 1.1$ & $0.29 \pm 0.74$ & $1.4 \pm 1.1^{\ddagger}$ \\
\hline Traditional food stores ${ }^{\#}$ & $0.89 \pm 1.1$ & $0.61 \pm 1.1$ & $0.54 \pm 0.99$ & $1.8 \pm 0.97^{\ddagger}$ \\
\hline Convenience stores & $5.3 \pm 7.2$ & $4.7 \pm 7.5$ & $2.8 \pm 4.9$ & $10.4 \pm 7.8^{\ddagger}$ \\
\hline Non-traditional food store ${ }^{* *}$ & $1.1 \pm 1.7$ & $1.0 \pm 1.8$ & $0.52 \pm 1.2$ & $2.3 \pm 1.8^{\S}$ \\
\hline \multicolumn{5}{|l|}{ Coverage - $5 \mathrm{mi}$} \\
\hline Supermarket & $0.83 \pm 1.1$ & $0.81 \pm 1.2$ & $0.5 \pm 0.87$ & $1.4 \pm 1.1^{\ddagger}$ \\
\hline Traditional food stores ${ }^{\#}$ & $1.2 \pm 1.1$ & $0.92 \pm 1.3$ & $0.94 \pm 1.1$ & $1.8 \pm 0.97^{\ddagger}$ \\
\hline Convenience stores & $7.3 \pm 8.1$ & $7.5 \pm 9.4$ & $4.9 \pm 6.1$ & $11.2 \pm 8.6^{\S}$ \\
\hline Non-traditional food store ${ }^{* *}$ & $1.4 \pm 1.8$ & $1.4 \pm 2.1$ & $0.88 \pm 1.4$ & $2.3 \pm 1.8^{\pi}$ \\
\hline \multicolumn{5}{|l|}{ Coverage - $10 \mathrm{mi}$} \\
\hline Supermarket & $1.4 \pm 1.1$ & $1.4 \pm 1.2$ & $1.1 \pm 0.97$ & $1.8 \pm 0.91$ \\
\hline Traditional food stores ${ }^{\#}$ & $2.1 \pm 1.2$ & $2.0 \pm 1.4$ & $1.9 \pm 1.1$ & $2.5 \pm 0.89$ \\
\hline Convenience stores & $13.8 \pm 9.8$ & $15.4 \pm 11.2$ & $11.9 \pm 8.5$ & $15.5 \pm 10.2$ \\
\hline Non-traditional food store ${ }^{* *}$ & $2.2 \pm 1.7$ & $2.5 \pm 1.9$ & $1.8 \pm 1.5$ & $2.6 \pm 1.6$ \\
\hline
\end{tabular}

$\mathrm{FPL}=$ Federal Poverty Level. ${ }^{*}$ Values calculated for each of the CBG (census block group) in the study area $(n=101)$. Proximity determined by the network distance from each CBG population-weighted centroid to the nearest food store; coverage is determined by the number of food stores within a specific network-based distance. Distance (proximity), numbers (coverage), and percentages (socioeconomic characteristics are shown as mean \pm standard deviation overall and by category of deprivation. ${ }^{\dagger}$ Items included in the Neighborhood Socioeconomic Deprivation Index.

Level of statistical significance for test for trend across ordered groups of neighborhood socioeconomic deprivation: ${ }^{\ddagger} p<0.05{ }^{\S} p<0.01{ }^{\natural} p<0.001$.

"Traditional food stores include all supercenters, supermarkets, and grocery stores.

**Non-traditional food stores include all dollar stores, mass merchandisers, and pharmacies that sell food items.

deprivation neighborhoods. Access, regardless of level of neighborhood deprivation, was better for a good variety of fresh and processed fruits or vegetables than for a good variety of fresh alone. Chloropleth maps (Figures 3 and 4) illustrate the spatial distribution of potential access to good varieties of fresh fruits and vegetables and neighborhoods with medium and high socioeconomic deprivation. The darkest color area indicates
CBG that are greater than 10 miles one-way to the nearest food store with a good selection of fresh fruits (16.7\% of medium and $11.1 \%$ of high deprivation areas) or vegetables $(18.8 \%$ of medium and $14.8 \%$ of high deprivation areas). Table 7 and 8 show proximity and coverage of supermarkets, traditional food stores, and food stores with a good variety of fruits or vegetables by area-level vehicle ownership. Areas with lowest vehicle 
Table 3 Percent and number of CBG at least 10 miles from a supermarket or traditional food store

\begin{tabular}{|c|c|c|c|c|}
\hline & \multicolumn{2}{|c|}{$\geq 10$ miles } & \multirow{2}{*}{$\begin{array}{c}\geq 15 \text { miles } \\
\text { supermarket }\end{array}$} & \multirow{2}{*}{$\begin{array}{c}\geq 20 \text { miles } \\
\text { supermarke }\end{array}$} \\
\hline & supermarket & Traditional $^{*}$ & & \\
\hline CBG $(n=101)$ & $47.5(48)$ & $32.7(33)$ & $26.7(27)$ & $12.9(13)$ \\
\hline \multicolumn{5}{|l|}{$\%$ Vehicle Ownership $^{+}$} \\
\hline Low $(n=34$ CBG) & $29.4(10)$ & $17.6(6)$ & $17.6(6)$ & $5.9(2)$ \\
\hline Medium ( $n=32 \mathrm{CBG}$ ) & $59.4(19)$ & $40.6(13)$ & $40.6(13)$ & $18.7(6)$ \\
\hline High $(n=35 \mathrm{CBG})$ & $54.3(19)$ & $40.0(14)$ & $22.9(8)$ & $14.3(5)$ \\
\hline Low Income CBG $(n=42)$ & $40.5(17)$ & $28.6(12)$ & $19.1(8)$ & $4.8(2)$ \\
\hline Total Population $(119,654)$ & $39.3(47,039)$ & $27.0(32,342)$ & $20.7(24,744)$ & $10.5(12,519)$ \\
\hline \multicolumn{5}{|l|}{ Socioeconomic Deprivation } \\
\hline Low $(n=27$ CBG) & $55.6(15)$ & $44.4(12)$ & $29.6(8)$ & $18.5(5)$ \\
\hline Medium ( $n=48 \mathrm{CBG}$ ) & $58.3(28)$ & $39.6(19)$ & $31.2(15)$ & $14.6(7)$ \\
\hline $\operatorname{High}(n=27 \mathrm{CBG})$ & $18.5(5)$ & $7.4(2)$ & $14.8(4)$ & $3.7(1)$ \\
\hline
\end{tabular}

CBG = census block group * Traditional food store = supercenter, supermarket, or grocery store.

${ }^{+}$Percent of CBG occupied households with access to a vehicle: Low $=<90.5 \%$; Medium = 90.5-95.4\%; and High $=>95.4 \%$.

ownership had relatively better access to food stores and fruits or vegetables. Figures 5 and 6 indicate those areas with low ( $>9.5 \%$ of occupied households without a vehicle) or medium (4.6-9.5\% without a vehicle) vehicle access. More than $20 \%$ of low vehicle access areas lacked access to fresh fruits and $23.5 \%$ to fresh vegetables within 10 miles. Chloropleth maps (see Figures 7, 8, 9, and 10) show access improved when fresh and processed fruits or vegetables were combined into overall fruits or vegetables. Still, there were areas where travel greater than 10 miles was necessary to access the nearest food store with a good variety of fresh or processed fruits or vegetables.

\section{Multivariate models for access}

Multivariate linear regression models were used to examine the relationship between neighborhood socioeconomic deprivation or vehicle ownership and access to a good variety of fruits or vegetables, controlling for population density. Table 9 shows that residents in high deprivation or low vehicle ownership areas, compared with low deprivation or high vehicle ownership areas, had to travel a significantly shorter distance to the nearest food store for fruits or vegetables. Population density was significant; the greater the population density, the better the access to the nearest fruits or vegetable opportunity. A similar relationship for 3-mile coverage is shown in Table 10 and for 5 -mile coverage in Table 11. High deprivation or low vehicle ownership areas were associated with a greater number of shopping opportunities for fruits or vegetables. As with the prior analysis, increasing population density was similarly associated with greater coverage.

\section{Discussion}

Findings from this study extend our understanding of potential spatial access from rural neighborhoods, not just to supermarkets, but to all food stores that market fruits and vegetables. We examined two dimensions of access: 1) proximity or distance to the nearest food store that offers a good variety of fruits or vegetables, and 2) coverage or the number of shopping opportunities for fruits or vegetables within a specified distance of the neighborhood. This is apparently the first study, to our knowledge, that uses ground-based data on the availability of fresh and processed (canned, frozen, and $100 \%$ juice) fruits and vegetables from traditional, convenience, and non-traditional food stores to examine access and availability of fruits and vegetables and the relationship between area inequalities (area-level socioeconomic deprivation or vehicle ownership) and access to fruits and vegetables, especially in a large rural area. Our analyses not only revealed that rural residents had relatively better access, in terms of closer distance and greater number of shopping opportunities, to a good selection of fruits or vegetables than to the nearest supermarket, but that access to fruits and vegetables was generally better for residents of high deprivation or low vehicle ownership neighborhoods. Several of the findings warrant further mention.

\section{Availability of fruits and vegetables}

Fresh fruits and vegetables were available in all traditional food stores (supercenters, supermarkets, and grocery stores) and in none of the non-traditional food stores (dollar stores, mass merchandisers, and pharmacy); however, $6 \%(n=9)$ of 140 convenience stores marketed both fresh fruits and vegetables and $22 \%$ marketed either fresh fruits or vegetables. The inclusion of healthier canned fruits expanded the picture of availability to include all non-traditional food stores and $48 \%$ of convenience stores. All non-traditional food stores and $90 \%$ of convenience stores marketed canned vegetables. 
Table 4 Scores for availability and variety of fresh and processed fruits and vegetables by food store type $(n=185)$

\begin{tabular}{|c|c|c|c|c|c|c|c|}
\hline & \multicolumn{3}{|c|}{ Traditional Food Stores } & \multirow{2}{*}{$\begin{array}{c}\text { Convenience Food Stores } \\
\text { Convenience } \\
(n=140) \%\end{array}$} & \multicolumn{3}{|c|}{ Non-Traditional Food Stores } \\
\hline & $\begin{array}{c}\text { Supercenter } \\
(n=1) \%\end{array}$ & $\begin{array}{c}\text { Supermarket } \\
(n=11) \%\end{array}$ & $\begin{array}{c}\text { Grocery } \\
(n=12) \%\end{array}$ & & $\begin{array}{c}\text { Dollar } \\
(n=16) \%\end{array}$ & $\begin{array}{c}\text { Mass } \\
(n=4) \%\end{array}$ & $\begin{array}{l}\text { Pharmacy } \\
(n=1) \%\end{array}$ \\
\hline \multicolumn{8}{|l|}{ Fruits } \\
\hline \multicolumn{8}{|l|}{ Fresh } \\
\hline 0 & 0 & 0 & 0 & 85 & 100 & 100 & 100 \\
\hline $1=1-4$ & 0 & 0 & 25.0 & 14.3 & 0 & 0 & 0 \\
\hline $2=\geq 5$ & 100 & 100 & 75.0 & 0.7 & 0 & 0 & 0 \\
\hline \multicolumn{8}{|l|}{ Processed } \\
\hline \multicolumn{8}{|c|}{ Canned in natural juice } \\
\hline 0 & 0 & 0 & 0 & 63.6 & 25.0 & 0 & 0 \\
\hline $1=1-4$ & 0 & 0 & 33.3 & 33.6 & 75.0 & 100 & 100 \\
\hline $2=\geq 5$ & 100 & 100 & 66.7 & 2.9 & 0 & 0 & 0 \\
\hline \multicolumn{8}{|c|}{ Canned in light syrup } \\
\hline 0 & 0 & 0 & 0 & 65.7 & 6.3 & 50.0 & 0 \\
\hline $1=1-4$ & 0 & 0 & 41.7 & 32.1 & 25.0 & 50.0 & 100 \\
\hline $2=\geq 5$ & 100 & 100 & 58.3 & 2.1 & 68.7 & 0 & 0 \\
\hline \multicolumn{8}{|l|}{ Frozen } \\
\hline 0 & 0 & 9.1 & 16.7 & 95.7 & 100 & 100 & 100 \\
\hline $1=1-4$ & 0 & 0 & 58.3 & 4.3 & 0 & 0 & 0 \\
\hline $2=\geq 5$ & 100 & 90.9 & 25.0 & 0 & 0 & 0 & 0 \\
\hline \multicolumn{8}{|c|}{ 100\% Fruit Juice } \\
\hline 0 & 0 & 0 & 0 & 3.6 & 0 & 0 & 0 \\
\hline $1=\geq 1$ & 100 & 100 & 100 & 96.4 & 100 & 100 & 100 \\
\hline \multicolumn{8}{|l|}{ Vegetables } \\
\hline \multicolumn{8}{|l|}{ Fresh } \\
\hline 0 & 0 & 0 & 0 & 85.7 & 100 & 100 & 100 \\
\hline 1 & 0 & 0 & 8.3 & 11.4 & 0 & 0 & 0 \\
\hline 2 & 0 & 0 & 58.3 & 2.9 & 0 & 0 & 0 \\
\hline 3 & 100 & 100 & 33.3 & 0 & 0 & 0 & 0 \\
\hline \multicolumn{8}{|l|}{ Processed } \\
\hline \multicolumn{8}{|l|}{ Canned* } \\
\hline 0 & 0 & 0 & 0 & 25.0 & 6.2 & 0 & 0 \\
\hline 1 & 0 & 0 & 0 & 26.4 & 0 & 50.0 & 100 \\
\hline 2 & 0 & 0 & 0 & 20.0 & 0 & 25.0 & 0 \\
\hline 3 & 100 & 100 & 100 & 28.6 & 93.8 & 25.0 & 0 \\
\hline \multicolumn{8}{|l|}{ Frozen } \\
\hline 0 & 0 & 0 & 0 & 90.0 & 31.2 & 75.0 & 100 \\
\hline $1=1-4$ & 0 & 0 & 0 & 7.1 & 68.8 & 25.0 & 0 \\
\hline $2=\geq 5$ & 100 & 100 & 100 & 2.9 & 0 & 0 & 0 \\
\hline \multicolumn{8}{|c|}{ 100\% Vegetable Juice } \\
\hline 0 & 0 & 0 & 0 & 24.3 & 25.0 & 0 & 100 \\
\hline $1=\geq 1$ & 100 & 100 & 100 & 75.70 & 75.0 & 100 & 0 \\
\hline \multicolumn{8}{|c|}{ Summary Score ${ }^{\dagger}$} \\
\hline Fruit & 9 & $8.8 \pm 0.6^{\pi}$ & $7.1 \pm 1.7$ & $1.9 \pm 1.1$ & $3.4 \pm 0.6^{\ddagger}$ & $2.5 \pm 0.6$ & 3 \\
\hline Vegetables & 9 & $9 \pm 0^{n}$ & $8.2 \pm 0.6$ & $2.6 \pm 1.8$ & $4.2 \pm 1.0^{\ddagger}$ & $3 \pm 1.4$ & 1 \\
\hline
\end{tabular}

\footnotetext{
${ }^{\ddagger} 100 \%$ juice.

${ }^{*} 0=$ none; $1=1-4$ vegetables (none are dark green vegetables); $2=1-4$ vegetables (one dark green) or $5-9$ vegetables (none are dark green); $3=\geq 5$ vegetables (one dark green).

${ }^{\dagger}$ Summary scores were created separately for fruit and vegetables by summing category scores for fresh and processed fruits or vegetables (reported as mean \pm SD).

${ }^{\ddagger}$ Statistically significant from convenience stores $(p<0.001)$ for fruits and vegetables $(p<0.01)$; and statistically significant from mass merchandisers for fruit $(p<0.05)$.

" Statistically significant from grocery stores $(p<0.001)$.
} 
Table 5 Level of availability and variety of fresh and processed fruits and vegetables by food store type

\begin{tabular}{|c|c|c|c|c|c|c|c|}
\hline & \multicolumn{3}{|c|}{ Traditional Food Stores } & \multirow{2}{*}{$\begin{array}{c}\text { Convenience Food Stores } \\
\text { Convenience } \\
(n=140) \%\end{array}$} & \multicolumn{3}{|c|}{ Non-Traditional Food Stores } \\
\hline & $\begin{array}{c}\text { Supercenter } \\
(n=1) \%\end{array}$ & $\begin{array}{c}\text { Supermarket } \\
(n=11) \%\end{array}$ & $\begin{array}{c}\text { Grocery } \\
(n=12) \%\end{array}$ & & $\begin{array}{c}\text { Dollar } \\
(n=16) \%\end{array}$ & $\begin{array}{c}\text { Mass } \\
(n=4) \%\end{array}$ & $\begin{array}{l}\text { Pharmacy } \\
(n=1) \%\end{array}$ \\
\hline \multicolumn{8}{|l|}{ Fruit $^{*}$} \\
\hline Poor & 0 & 0 & 0 & 50.7 & 0 & 0 & 0 \\
\hline Medium & 0 & 0 & 0 & 39.3 & 56.2 & 100 & 100 \\
\hline Good & 100 & 100 & 100 & 10 & 43.8 & 0 & 0 \\
\hline \multicolumn{8}{|l|}{ Vegetable $^{\dagger}$} \\
\hline Poor & 0 & 0 & 0 & 32.1 & 6.2 & 0 & 100 \\
\hline Medium & 0 & 0 & 0 & 40.0 & 0 & 75.0 & 0 \\
\hline Good & 100 & 100 & 100 & 27.9 & 93.8 & 25.0 & 0 \\
\hline
\end{tabular}

* Fruit availability: Poor = summary score $0-1$; medium = summary score $2-3$; good = summary score $4-9$.

${ }^{+}$Vegetable availability: Poor = summary score $0-1$; medium = summary score 2-3; good = summary score 4-10.

The variety of fruits or vegetables was greater at supermarkets compared with grocery stores. Among nontraditional food stores, the largest variety was found at dollar stores, which was greater than that found at convenience stores. These results highlight the limitations of prior methods for examining fruit and vegetable availability which may misrepresent actual availability in a number of ways [17]. For example, prior work focused on supermarkets as sole source for fruits and vegetables and omitted non-traditional food stores, such as dollar stores or mass merchandisers, which are dramatically growing in numbers and increasing the opportunities for food and beverage shopping [65,90]. Over the past 10 years, dollar stores have increased the variety of lower-price shopping and food options to consumers [91-93]. According to the Nielsen Company, dollar stores are also attracting high and middle income shoppers, in addition to their primary customer - lowincome shoppers [90]. In addition to the dynamics of the retail food environment, the impact of the economic downturn and increased vehicle costs may alter food shopping patterns. Prior examinations of fruit and vegetable access failed to include the presence of canned or frozen forms even though dietary recommendations specify fresh, canned, frozen, or $100 \%$ juice [70]. Furthermore, the variety (i.e., the number of different types of fruits or vegetables) is often not considered as part of availability, which results in a lack of differentiation between a location having one type of fruit compared with multiple types of fruits.

\section{Spatial access}

Spatial access to a good variety of fresh or processed fruits or vegetables, using proximity (distance to the nearest food store) and coverage (number of shopping opportunities), was better for rural neighborhoods than access to the nearest supermarket. On average, rural neighborhoods (CBG) were 9.9 miles to the nearest supermarket, 7.0 miles to the nearest traditional food store (supercenter, supermarket, or grocery store), 6.7 miles and 7.4 miles to the nearest food store with a good variety of fresh fruits and vegetables, respectively, and 4.7 miles and 4.5 miles to a good variety of fresh and processed fruits or vegetables. As demonstrated in this study, the distance varied greatly depending whether access was to the nearest supermarket, the nearest food store regardless of type with a good variety fresh fruits or vegetables, or the nearest food store with a good variety of fresh and processed fruits or vegetables. Access to an available supply of fruits or vegetables provides a more realistic picture of rural access than distance alone to a supermarket or traditional food store, or store density for limited types of fresh fruits and vegetable $[36,57]$. Interestingly, the differences in distance remained significant for neighborhoods classified as having low or medium socioeconomic deprivation, but not for high deprivation, where proximity and coverage was generally best. High deprivation neighborhoods were located at a distance that would require access and resources for a car for transportation and where the largest percentage of occupied housing does not have an available vehicle. For neighborhoods with lower vehicle ownership, the median distance to a food store or selection of fruits or vegetables was beyond walking distance.

\section{Food deserts}

Food deserts have been described as areas, particularly lower income neighborhoods, with limited access to affordable and nutritious food [17]. In small-town and rural areas, food deserts have been defined as areas more than 10 miles from a supermarket [55,94]. The 10 mile threshold is considered "somewhat arbitrary, considering that without a car, any distance of more than a mile or so could be considered unacceptably far" [17]. As shown in the choloropleth maps, there were several medium and high deprivation neighborhoods that could be described as food deserts, where residents lacked access to supermarkets or to fresh or processed fruits or 
Table 6 Access to good availability of fresh and overall (fresh and processed) fruits and vegetables by neighborhood socioeconomic deprivation, using measures of proximity and coverage*

\begin{tabular}{|c|c|c|c|c|}
\hline & All Deprivation $(n=101)$ & Low Deprivation $(n=26)$ & Medium Deprivation $(n=48)$ & High Deprivation $(n=27)$ \\
\hline \multicolumn{5}{|l|}{ Proximity (in miles) } \\
\hline Supermarket & $9.9 \pm 8.5$ & $11.4 \pm 8.8$ & $12.1 \pm 8.0$ & $4.7 \pm 6.8$ \\
\hline \multicolumn{5}{|l|}{ Fruits } \\
\hline Fresh fruits & $6.7 \pm 5.7^{\S}$ & $8.1 \pm 5.2^{n}$ & $8.0 \pm 5.4^{\S}$ & $2.9 \pm 5.1^{\ddagger}$ \\
\hline Overall fruits & $4.7 \pm 4.2^{\S}$ & $5.6 \pm 3.8^{q}$ & $5.8 \pm 4.0^{\S}$ & $2.0 \pm 4.0^{\ddagger}$ \\
\hline \multicolumn{5}{|l|}{ Vegetables } \\
\hline Fresh vegetables & $7.4 \pm 6.1^{\S}$ & $8.6 \pm 5.6^{q}$ & $8.8 \pm 5.7^{\S}$ & $4.0 \pm 6.1^{\ddagger}$ \\
\hline Overall vegetables & $4.5 \pm 4.1^{\S}$ & $5.4 \pm 3.6^{\pi}$ & $5.3 \pm 3.9^{\S}$ & $2.1 \pm 4.0^{\ddagger}$ \\
\hline \multicolumn{5}{|l|}{ Coverage - 1 mile } \\
\hline \multicolumn{5}{|l|}{ Fruits } \\
\hline Fresh fruits & $0.47 \pm 0.82$ & $0.65 \pm 1.16$ & $0.50 \pm 0.99$ & $1.89 \pm 1.12^{\ddagger}$ \\
\hline Overall fruits & $0.77 \pm 1.3$ & $0.96 \pm 1.51$ & $0.79 \pm 1.29$ & $2.81 \pm 1.73^{\ddagger}$ \\
\hline \multicolumn{5}{|l|}{ Vegetables } \\
\hline Fresh vegetables & $0.37 \pm 0.64$ & $0.61 \pm 1.1$ & $0.35 \pm 0.76$ & $1.59 \pm 1.08^{\ddagger}$ \\
\hline Overall vegetables & $0.59 \pm 0.98$ & $0.85 \pm 1.22$ & $0.69 \pm 1.07$ & $2.30 \pm 1.23^{\ddagger}$ \\
\hline \multicolumn{5}{|l|}{ Coverage -3 miles } \\
\hline \multicolumn{5}{|l|}{ Fruits } \\
\hline Fresh fruits & $0.91 \pm 1.2$ & $0.65 \pm 1.16$ & $0.50 \pm 0.99$ & $1.89 \pm 1.12^{\ddagger}$ \\
\hline Overall fruits & $1.4 \pm 1.7$ & $0.96 \pm 1.51$ & $0.79 \pm 1.29$ & $2.81 \pm 1.73^{\ddagger}$ \\
\hline \multicolumn{5}{|l|}{ Vegetables } \\
\hline Fresh vegetables & $0.91 \pm 1.2$ & $0.61 \pm 1.1$ & $0.35 \pm 0.76$ & $1.59 \pm 1.08^{\ddagger}$ \\
\hline Overall vegetables & $1.2 \pm 1.3$ & $0.85 \pm 1.22$ & $0.69 \pm 1.07$ & $2.30 \pm 1.23^{\ddagger}$ \\
\hline \multicolumn{5}{|l|}{ Coverage -5 miles } \\
\hline \multicolumn{5}{|l|}{ Fruits } \\
\hline Fresh fruits & $1.2 \pm 1.3$ & $1.0 \pm 1.36$ & $0.87 \pm 1.18$ & $1.89 \pm 1.12^{\dagger}$ \\
\hline Overall fruits & $1.9 \pm 1.8$ & $1.5 \pm 1.82$ & $1.52 \pm 1.61$ & $2.85 \pm 1.72^{\dagger}$ \\
\hline \multicolumn{5}{|l|}{ Vegetables } \\
\hline Fresh vegetables & $0.93 \pm 1.1$ & $0.88 \pm 1.27$ & $0.58 \pm 0.92$ & $1.59 \pm 1.08^{\dagger}$ \\
\hline Overall vegetables & $1.6 \pm 1.4$ & $1.30 \pm 1.40$ & $1.39 \pm 1.35$ & $2.37 \pm 1.24^{+}$ \\
\hline \multicolumn{5}{|l|}{ Coverage -10 miles } \\
\hline \multicolumn{5}{|l|}{ Fruits } \\
\hline Fresh fruits & $2.1 \pm 1.2$ & $2.08 \pm 1.29$ & $1.90 \pm 1.22$ & $2.52 \pm 1.19$ \\
\hline Overall fruits & $3.4 \pm 1.8$ & $3.58 \pm 1.63$ & $3.14 \pm 1.80$ & $3.70 \pm 1.75$ \\
\hline \multicolumn{5}{|l|}{ Vegetables } \\
\hline Fresh vegetables & $1.5 \pm 1.0$ & $1.65 \pm 1.16$ & $1.31 \pm 0.93$ & $1.81 \pm 0.96$ \\
\hline Overall vegetables & $3.3 \pm 1.5$ & $3.35 \pm 1.41$ & $3.04 \pm 1.58$ & $3.59 \pm 1.52$ \\
\hline
\end{tabular}

* Network distance shown as mean \pm standard deviation; median in parenthesis.

Level of statistical significance for test for trend across ordered groups of neighborhood socioeconomic deprivation: ${ }^{\dagger} p<0.01{ }^{\ddagger} p<0.001$.

Different than distance to nearest supermarket ${ }^{\S} p<0.001{ }^{\circledR} p<0.01$.

vegetables [95]. Maps also illustrated vehicle ownership areas where food stores or supplies of fruits or vegetables were not accessible.

\section{Neighborhood Inequalities and Access}

Finally, the findings from multivariate regression models confirmed that the most deprived or lowest vehicle ownership rural neighborhoods were not the most fooddisadvantaged neighborhoods. Compared with low deprivation or high vehicle ownership neighborhoods, high deprivation or low vehicle ownership neighborhoods had better spatial access to a good variety of fruits and vegetables, both in the distance to the nearest source for fruits or vegetables and in the number of shopping opportunities, after controlling for the influence of neighborhood population density. Population density was included in the models, based on prior work in rural areas that found that food stores were located in closer proximity to neighborhoods or communities with greater population density $[36,96]$.

It has been suggested that poorer quality neighborhoods amplify individual disadvantages through poorer 


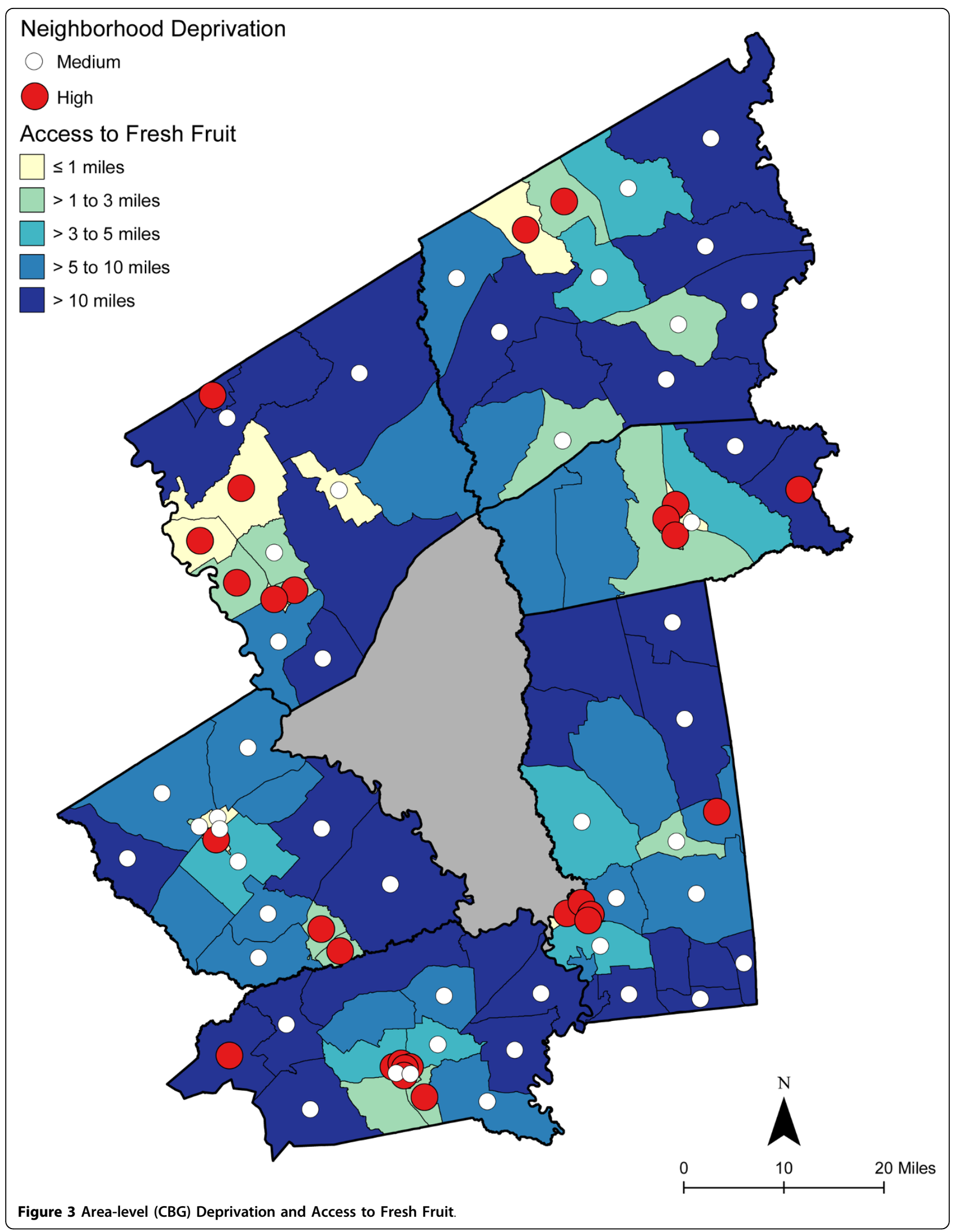




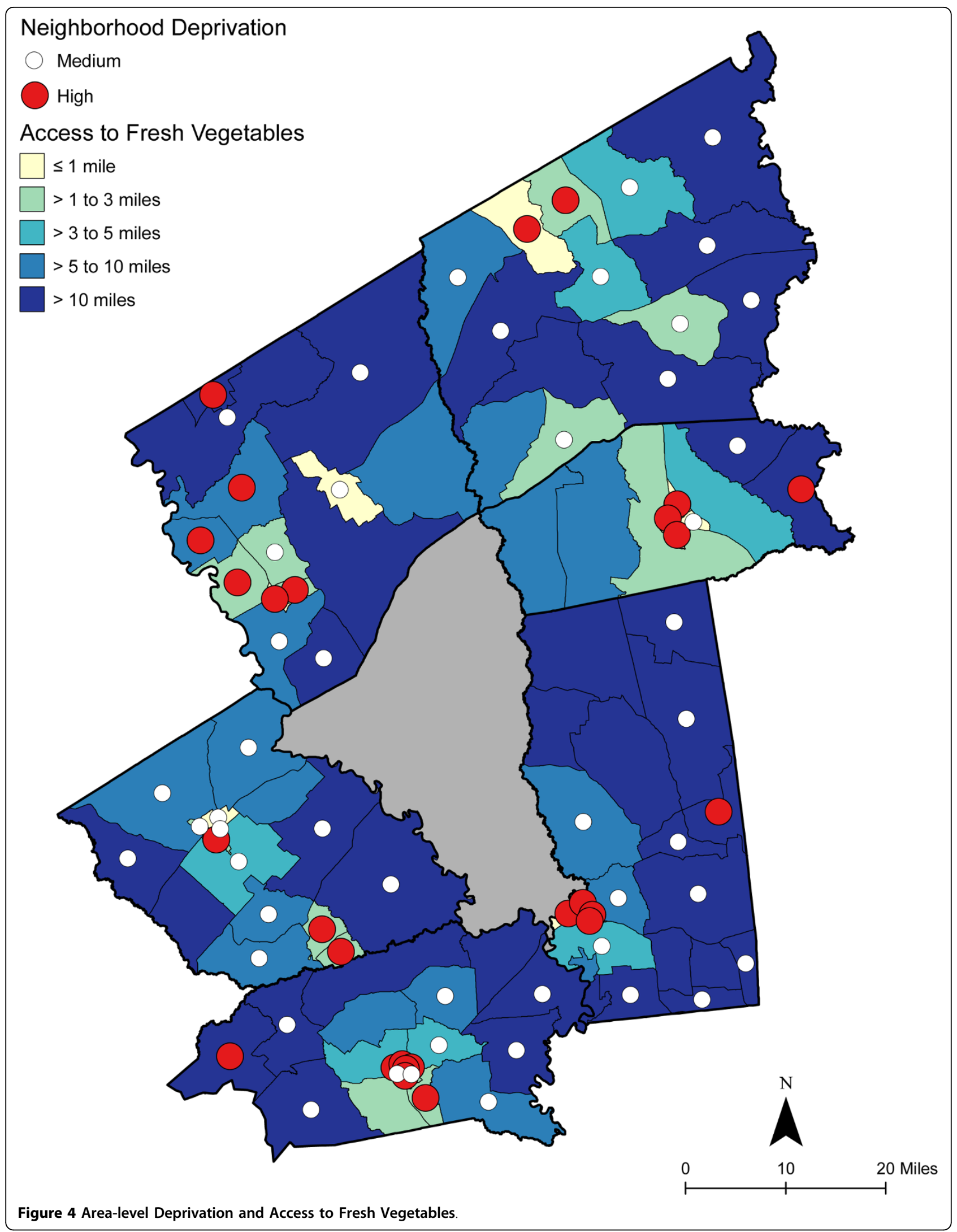


Table 7 Spatial accessibility to fruits and vegetables by area-level vehicle ownership, using measures of proximity*

\begin{tabular}{|c|c|c|c|}
\hline & Low Vehicle Ownership $(n=35)$ & Medium Vehicle Ownership $(n=32)$ & High Vehicle Ownership $(n=34)$ \\
\hline \multicolumn{4}{|l|}{ SPATIAL ACCESSIBILITY } \\
\hline \multicolumn{4}{|l|}{ Proximity, mi } \\
\hline \multicolumn{4}{|l|}{ Food stores } \\
\hline Supermarket & $6.4 \pm 7.8^{\S}(1.4 ; 0.3-23.8)$ & $12.4 \pm 8.4(11.6 ; 0.6-30.9)$ & $11.1 \pm 8.2(10.5 ; 0.1-33.6)$ \\
\hline Traditional food store & $4.1 \pm 6.2^{1}(1.1 ; 0.1-23.1)$ & $6.4 \pm 7.8(7.4 ; 0.6-24.4)$ & $6.4 \pm 7.8(9.1 ; 0.1-19.0)$ \\
\hline \multicolumn{4}{|l|}{ Fruits } \\
\hline Fresh fruits & $4.0 \pm 5.5^{\S}(1.1 ; 0.1-19.5)$ & $8.9 \pm 6.2(9.3 ; 0.8-19.8)$ & $7.3 \pm 4.3(8.0 ; 0.1-15.1)$ \\
\hline Overall fruits & $2.7 \pm 4.2^{\natural}(0.9 ; 0.1-19.5)$ & $4.8 \pm 3.3(4.4 ; 0.5-12.4)$ & $6.7 \pm 4.1(6.9 ; 0.1-14.6)$ \\
\hline \multicolumn{4}{|l|}{ Vegetables } \\
\hline Fresh vegetables & $4.8 \pm 6.7^{\S}(1.2 ; 0.4-23.1)$ & $9.7 \pm 6.5(9.5 ; 0.8-23.5)$ & $8.1 \pm 4.5(9.3 ; 0.1-16.3)$ \\
\hline Overall vegetables & $2.5 \pm 3.9^{\natural}(1.0 ; 0.1-19.5)$ & $5.3 \pm 3.8(4.5 ; 0.5-12.9)$ & $5.7 \pm 3.8(5.6 ; 0.1-14.6)$ \\
\hline
\end{tabular}

Area-level (CBG) vehicle ownership (\% owner-occupied households): Low $=<90.5 \%$; medium $=90.5-95.4 \%$; high $=>95.4 \%$. ${ }^{*}$ Values calculated for each of the CBG (census block group) in the study area $(n=101)$. Proximity determined by the network distance from each CBG population-weighted centroid to the nearest food store. Distance (proximity) and percentages (mean \pm standard deviation, median, and range) by category of vehicle ownership.

Level of statistical significance for test for trend across ordered groups of area = -level vehicle ownership: ${ }^{\ddagger} p<0.05{ }^{\S} p<0.01{ }^{\natural} p<0.001$.

Table 8 Spatial accessibility to fruits and vegetables by area-level vehicle ownership, using measures of coverage*

\begin{tabular}{|c|c|c|c|}
\hline & Low Vehicle Ownership $(n=35)$ & Medium Vehicle Ownership $(n=32)$ & High Vehicle Ownership $(n=34)$ \\
\hline \multicolumn{4}{|l|}{ SPATIAL ACCESSIBILITY } \\
\hline \multicolumn{4}{|l|}{ Coverage - $3 \mathrm{mi}$} \\
\hline \multicolumn{4}{|l|}{ Food stores } \\
\hline Supermarket & $1.2 \pm 1.1^{\pi}(1 ; 0-3)$ & $0.4 \pm 0.9(0 ; 0-3)$ & $0.5 \pm 0.9(0 ; 0-3)$ \\
\hline Traditional & $1.6 \pm 1.1^{\natural}(2 ; 0-2)$ & $0.5 \pm 0.9(0 ; 0-3)$ & $0.6 \pm 1.0(0 ; 0-3)$ \\
\hline \multicolumn{4}{|l|}{ Fruits } \\
\hline Fresh fruits & $1.7 \pm 1.2^{n}(2 ; 0-3)$ & $0.4 \pm 0.9(0 ; 0-3)$ & $0.6 \pm 1.1(0 ; 0-3)$ \\
\hline Overall fruits & $2.6 \pm 1.8^{\S}(3 ; 0-6)$ & $0.8 \pm 1.1(0 ; 0-3)$ & $0.8 \pm 1.4(0 ; 0-6)$ \\
\hline \multicolumn{4}{|l|}{ Vegetables } \\
\hline Fresh vegetable & $1.3 \pm 1.1^{\S}(1 ; 0-3)$ & $0.4 \pm 0.9(0 ; 0-3)$ & $0.5 \pm 0.9(0 ; 0-3)$ \\
\hline Overall vegetables & $2.0 \pm 1.4^{\natural}(2.5 ; 0-4)$ & $0.7 \pm 1.0(0 ; 0-3)$ & $0.8 \pm 1.2(0 ; 0-4)$ \\
\hline \multicolumn{4}{|l|}{ Coverage - $5 \mathrm{mi}$} \\
\hline \multicolumn{4}{|l|}{ Food stores } \\
\hline Supermarket & $1.2 \pm 1.1^{\ddagger}(1 ; 0-3)$ & $0.6 \pm 1.0(0 ; 0-3)$ & $0.7 \pm 1.1(0 ; 0-3)$ \\
\hline Traditional & $1.7 \pm 1.1^{\natural}(2 ; 0-3)$ & $0.9 \pm 1.0(1 ; 0-3)$ & $0.9 \pm 1.2(0 ; 0-3)$ \\
\hline \multicolumn{4}{|l|}{ Fruits } \\
\hline Fresh fruits & $1.8 \pm 1.2^{\S}(2 ; 0-3)$ & $0.8 \pm 1.1(0 ; 0-3)$ & $0.9 \pm 1.3(0 ; 0-3)$ \\
\hline Overall fruits & $2.7 \pm 1.7^{\S}(3 ; 0-6)$ & $1.5 \pm 1.4(1 ; 0-6)$ & $1.3 \pm 1.9(0 ; 0-6)$ \\
\hline \multicolumn{4}{|l|}{ Vegetables } \\
\hline Fresh vegetables & $1.4 \pm 1.1^{\ddagger}(1 ; 0-3)$ & $0.7 \pm 1.1(0 ; 0-3)$ & $0.7 \pm 1.1() 0 ; 0-3)$ \\
\hline Overall vegetables & $2.3 \pm 1.4^{n}(3 ; 0-4)$ & $1.3 \pm 1.1(1 ; 0-4)$ & $1.3 \pm 1.4(1 ; 0-4)$ \\
\hline \multicolumn{4}{|l|}{ Coverage - $10 \mathrm{mi}$} \\
\hline \multicolumn{4}{|l|}{ Food stores } \\
\hline Supermarket & $1.5 \pm 1.0(2 ; 0-3)$ & $1.2 \pm 1.0(1 ; 0-3)$ & $1.5 \pm 1.1(1 ; 0-4)$ \\
\hline Traditional & $2.3 \pm 1.0(3 ; 0-4)$ & $1.7 \pm 1.0(2 ; 0-4)$ & $2.2 \pm 1.3(2 ; 0-5)$ \\
\hline \multicolumn{4}{|l|}{ Fruits } \\
\hline Fresh fruits & $2.3 \pm 1.3(3 ; 0-4)$ & $1.7 \pm 1.1(2 ; 0-3)$ & $2.3 \pm 1.3(3 ; 0-4)$ \\
\hline Overall fruits & $3.6 \pm 1.8(3 ; 0-7)$ & $3 \pm 1.5(3 ; 1-7)$ & $3.6 \pm 1.9(3 ; 0-8)$ \\
\hline \multicolumn{4}{|l|}{ Vegetables } \\
\hline Fresh vegetables & $1.6 \pm 1.0(2 ; 0-3)$ & $1.3 \pm 1.0(1 ; 0-3)$ & $1.6 \pm 1.1(2 ; 0-4)$ \\
\hline Overall vegetables & $3.4 \pm 1.6(4 ; 0-6)$ & $2.8 \pm 1.3(3 ; 1-5)$ & $3.4 \pm 1.5(3 ; 0-6)$ \\
\hline
\end{tabular}

Area-level (CBG) vehicle ownership (\% owner-occupied households): Low $=<90.5 \%$; medium $=90.5-95.4 \%$; high $=>95.4 \%$. ${ }^{*}$ Values calculated for each of the CBG (census block group) in the study area $(n=101)$. Coverage is determined by the number of food stores within a specific network-based distance. Numbers (coverage) and percentages (mean \pm standard deviation, median, and range) by category of vehicle ownership.

Level of statistical significance for test for trend across ordered groups of area = -level vehicle ownership: ${ }^{\ddagger} p<0.05{ }^{\S} p<0.01{ }^{n} p<0.001$. 


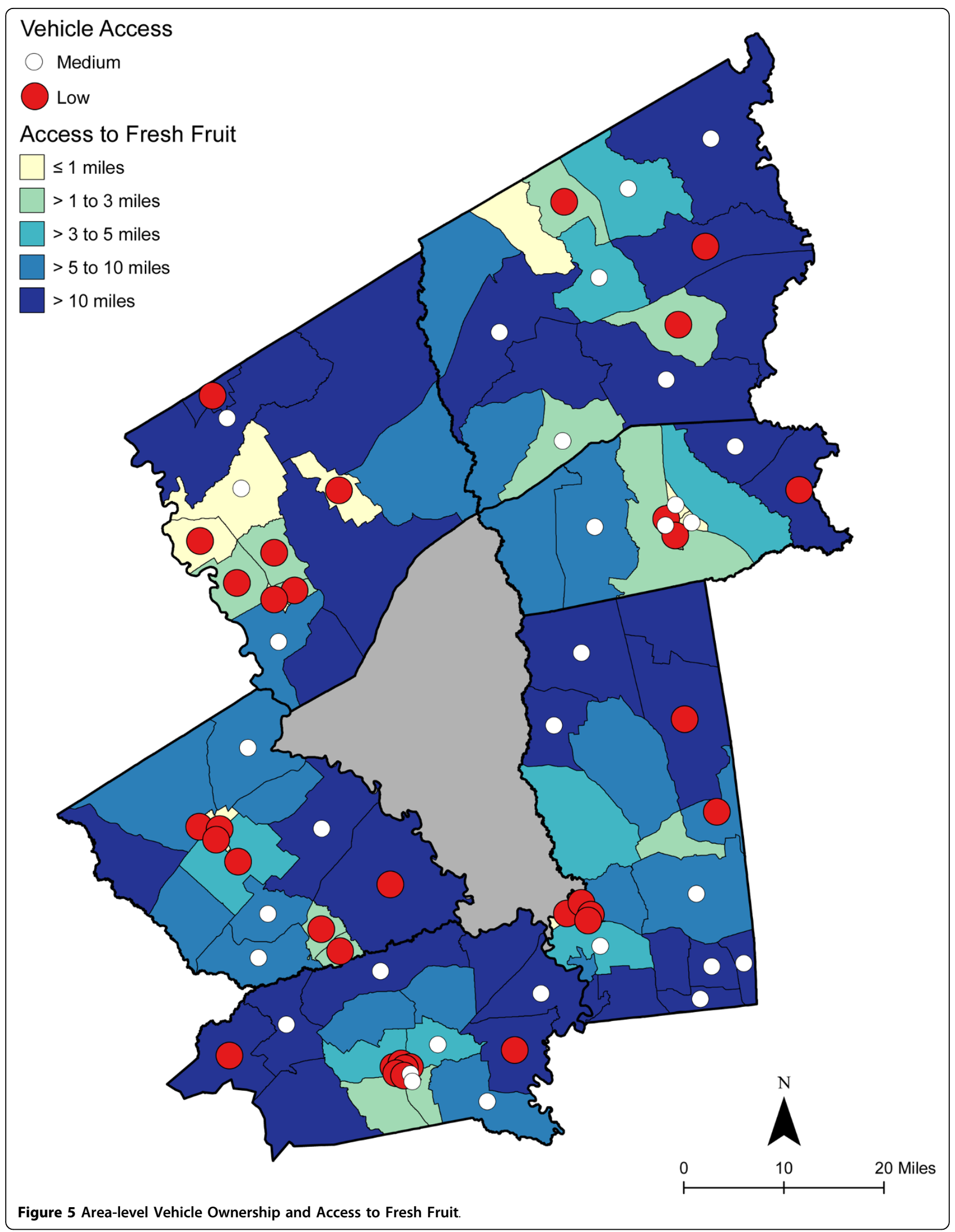




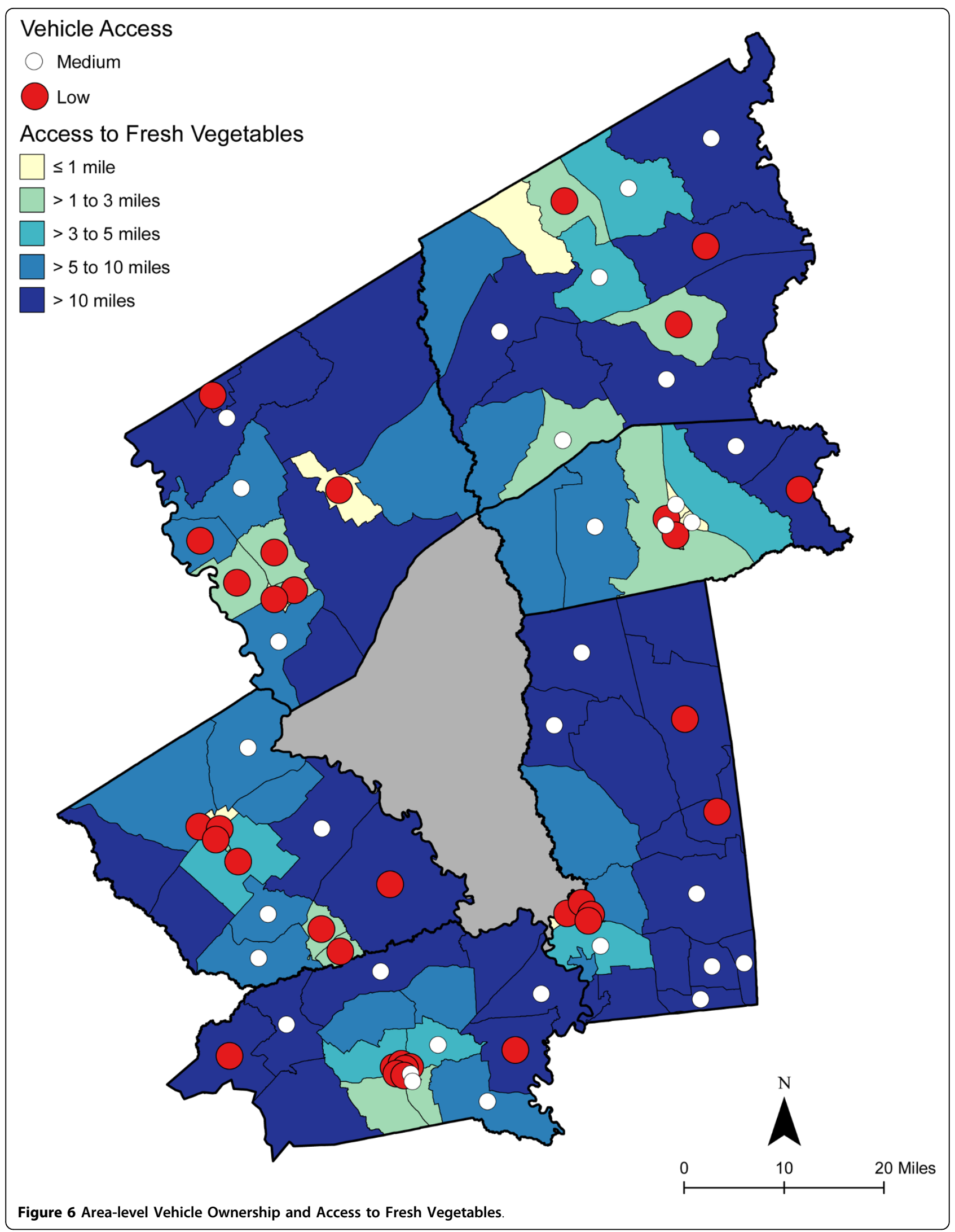




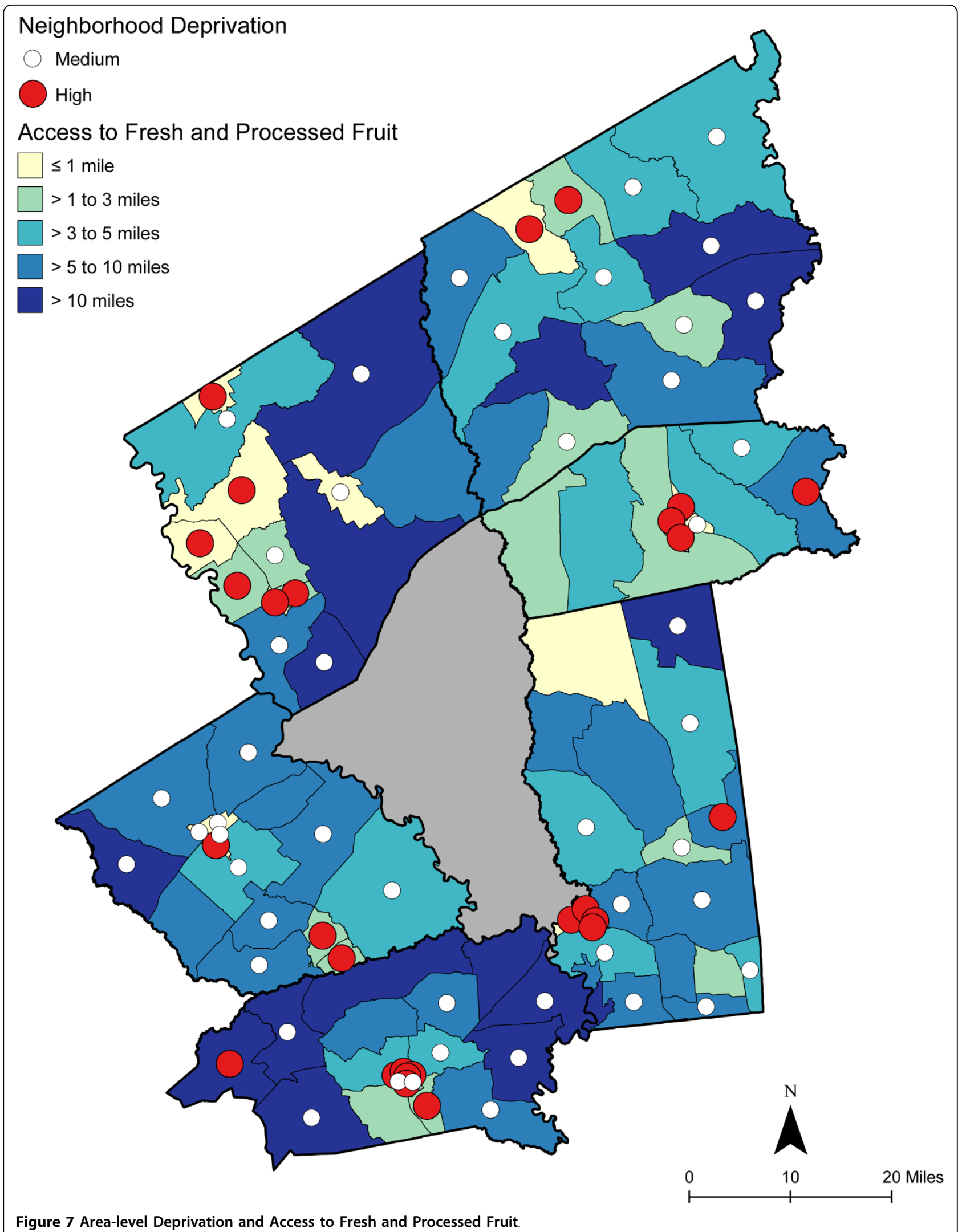




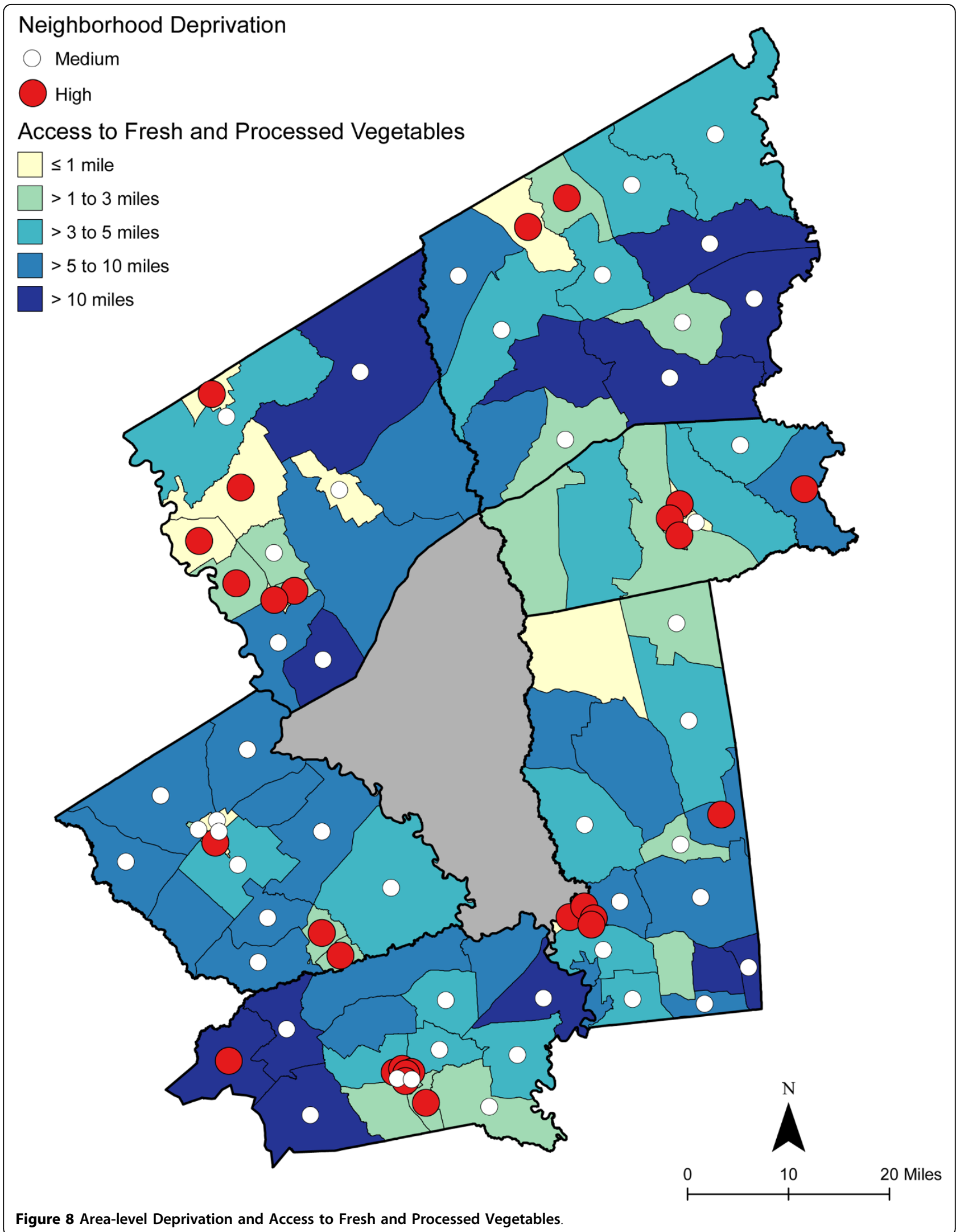




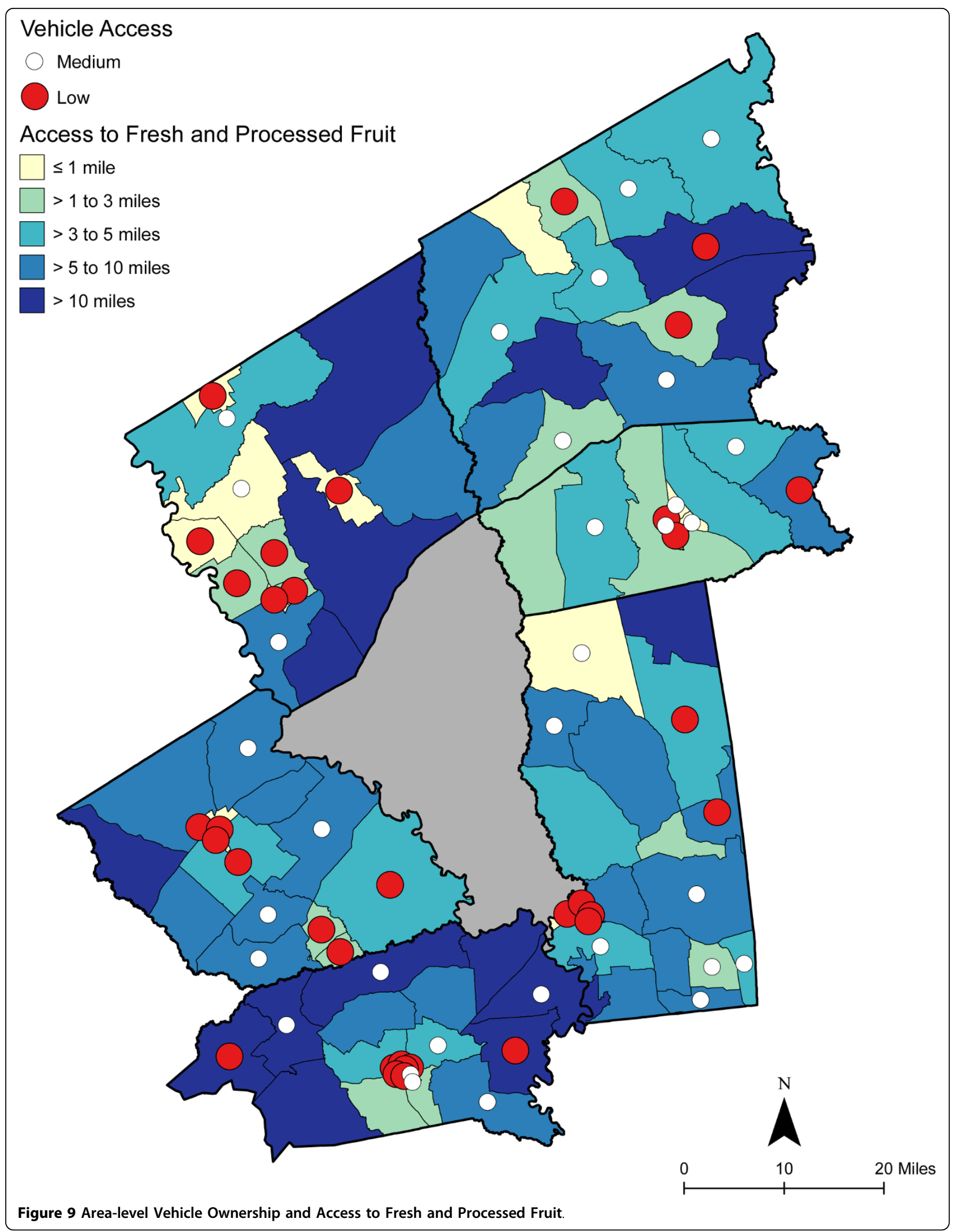




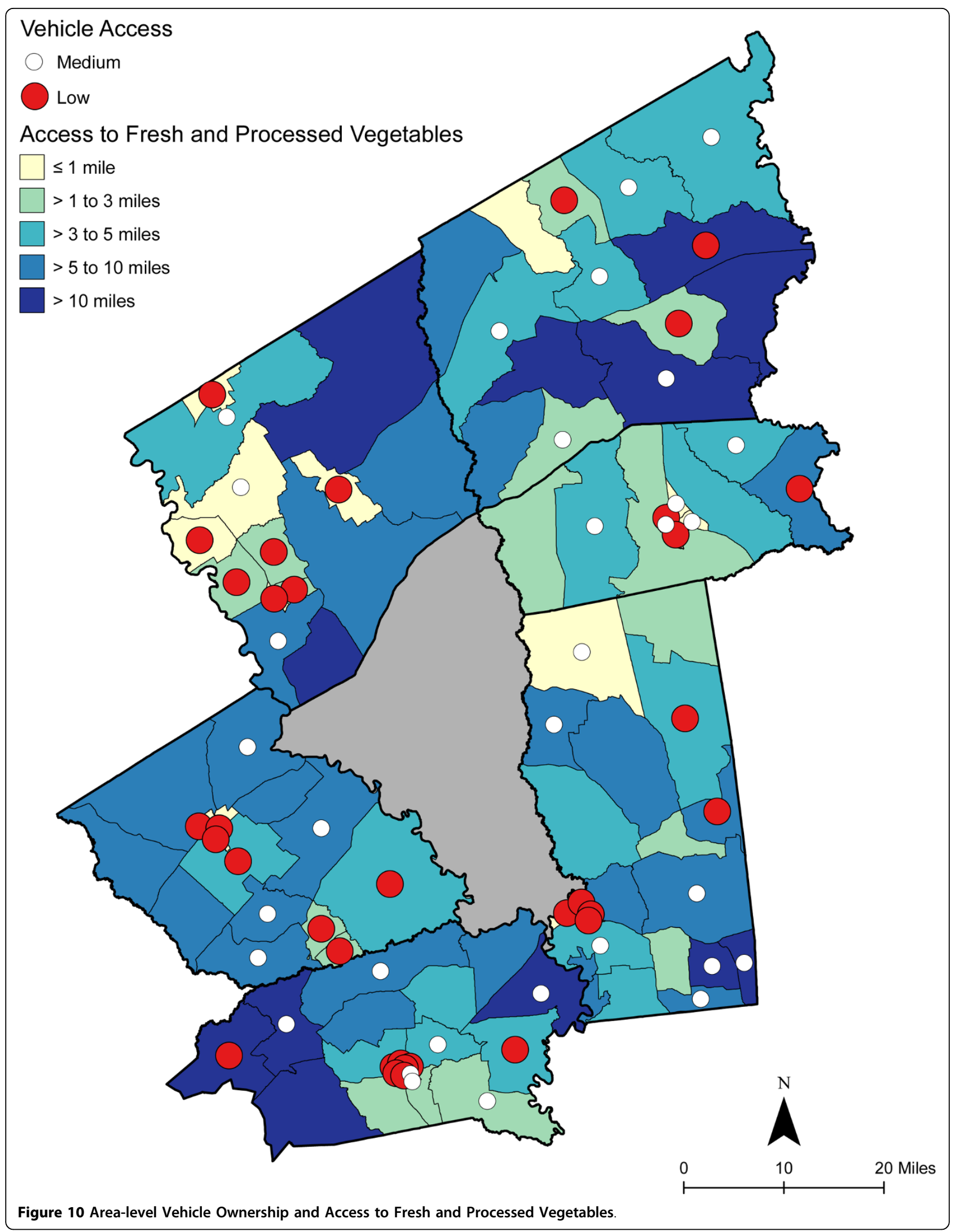


Table 9 Association between proximity to a good selection of fruits and vegetables and area deprivation or vehicle ownership, using multivariate linear regression model

\begin{tabular}{|c|c|c|c|c|}
\hline \multirow[t]{2}{*}{ Model 1} & \multicolumn{4}{|c|}{ Access as network distance to the nearest } \\
\hline & Fresh fruits & Overall fruits & Fresh vegetables & Overall vegetables \\
\hline Deprivation & b (SE) & b (SE) & b (SE) & b (SE) \\
\hline High & $-4.47(0.134)^{\ddagger}$ & $-3.09(1.02)^{+}$ & $-3.82(1.44)^{\dagger}$ & $-2.91(1.0)^{\dagger}$ \\
\hline Medium & $-0.86(1.19)$ & $-0.33(0.91)$ & $-0.75(1.28)$ & $-0.55(0.89)$ \\
\hline$\overline{R^{2}}$ & 0.303 & 0.264 & 0.291 & 0.243 \\
\hline$P$ & $<0.001$ & $<0.001$ & $<0.001$ & $<0.001$ \\
\hline \multirow[t]{2}{*}{ Model 2} & \multicolumn{4}{|c|}{ Access as network distance to the nearest } \\
\hline & Fresh fruits & Overall fruits & Fresh vegetables & Overall vegetables \\
\hline Vehicle ownership & b (SE) & b (SE) & b (SE) & b (SE) \\
\hline Low & $-2.26(1.21)$ & $-3.21(0.90)^{\ddagger}$ & $-1.93(1.33)$ & $-2.56(0.89)^{\dagger}$ \\
\hline Medium & $1.23(1.21)$ & $-2.07(0.90)^{\ddagger}$ & $1.29(1.32)$ & $-0.66(0.89)$ \\
\hline$\overline{R^{2}}$ & 0.269 & 0.276 & 0.268 & 0.233 \\
\hline$P$ & $<0.001$ & $<0.001$ & $<0.001$ & $<0.001$ \\
\hline
\end{tabular}

NOTE: In models 1 and 2, the four equations were simultaneously estimated, controlling for population density. In model 1, deprivation entered as categorical variable; low deprivation is referent group. In model 2, vehicle ownership entered as categorical variable; high vehicle ownership is referent group. In both models, population density entered as continuous. Results are reported as multivariate-adjusted b (SE). Statistically significant variables are indicated as: ${ }^{*}<0.05^{\dagger}<0.01^{\ddagger}<0.001$.

Table 10 Association between 3-mile coverage of a good selection of fruits and vegetables and area deprivation or vehicle ownership, using multivariate linear regression model

\begin{tabular}{|c|c|c|c|c|}
\hline \multirow[t]{2}{*}{ Model 1} & \multicolumn{4}{|c|}{ Access as number of shopping opportunities within 3 network 3 miles } \\
\hline & Fresh fruits & Overall fruits & Fresh vegetables & Overall vegetables \\
\hline Deprivation & b (SE) & b (SE) & b (SE) & b (SE) \\
\hline High & $0.98(0.21)^{\ddagger}$ & $1.58(0.34)^{\ddagger}$ & $0.75(0.18)^{\ddagger}$ & $1.21(0.25)^{\ddagger}$ \\
\hline Medium & $0.11(0.18)$ & $0.12(0.30)$ & $-0.02(0.16)$ & $0.10(0.22)$ \\
\hline$\overline{R^{2}}$ & 0.633 & 0.497 & 0.660 & 0.562 \\
\hline P & $<0.001$ & $<0.001$ & $<0.001$ & $<0.001$ \\
\hline \multirow[t]{2}{*}{ Model 2} & \multicolumn{4}{|c|}{ Access as number of shopping opportunities within 3 network 3 miles } \\
\hline & Fresh fruits & Overall fruits & Fresh vegetables & Overall vegetables \\
\hline Vehicle ownership & b (SE) & b (SE) & b (SE) & b (SE) \\
\hline Low & $0.69(0.19)^{\ddagger}$ & $1.37(0.31)^{\ddagger}$ & $0.50(0.17)^{\dagger}$ & $0.88(0.23)^{\ddagger}$ \\
\hline Medium & $-0.05(0.19)$ & $0.13(0.31)$ & $0.02(0.17)$ & $-0.01(0.23)$ \\
\hline$\overline{R^{2}}$ & 0.598 & 0.475 & 0.610 & 0.516 \\
\hline$P$ & $<0.001$ & $<0.001$ & $<0.001$ & $<0.001$ \\
\hline
\end{tabular}

NOTE: In models 1 and 2, the four equations were simultaneously estimated, controlling for population density. In model 1, deprivation entered as categorical variable; low deprivation is referent group. In model 2, vehicle ownership entered as categorical variable; high vehicle ownership is referent group. In both models, population density entered as continuous. Results are reported as multivariate-adjusted b (SE). Statistically significant variables are indicated as: ${ }^{*}<0.05^{\dagger}<0.01{ }^{\ddagger}<0.001$.

access to healthy foods [21]. Key findings from this study add to the discussion and understanding of the influence of neighborhood inequalities on physical access to healthy foods. Access to food stores (primarily large supermarkets) has been studied in the U.S., U.K., Europe, Canada, Australia, and New Zealand, and with mixed results. In some studies, poor or minority areas provided little or no access to supermarkets [25,38,39,48,53,97-102]; other studies found little or no difference between deprived and affluent areas in access to supermarkets $[37,59,71,78,103,104]$, or better access from deprived neighborhoods $[36,60,61,104,105]$. Importantly, we followed the recommendation of Macdonald and colleagues [61] that the nutritional value of the foods available in food stores should be considered and not just the proximity or density of retail food stores. In fact, the U.S. Department of Agriculture's food guidance system in its dietary recommendations for fruits and vegetables identify canned, frozen, and $100 \%$ juice in addition to fresh as a way to help people achieve the recommended variety and amount of fruits and vegetables [70]. Supporting this is the research that confirmed 
Table 11 Association between 5-mile coverage of a good selection of fruits and vegetables and area deprivation or vehicle ownership, using multivariate linear regression model

\begin{tabular}{|c|c|c|c|c|}
\hline \multirow[t]{2}{*}{ Model 1} & \multicolumn{4}{|c|}{ Access as number of shopping opportunities within 3 network 3 miles } \\
\hline & Fresh fruits & Overall fruits & Fresh vegetables & Overall vegetables \\
\hline Deprivation & b (SE) & b (SE) & b (SE) & b (SE) \\
\hline High & $0.98(0.21)^{\ddagger}$ & $1.58(0.34)^{\ddagger}$ & $0.75(0.18)^{\ddagger}$ & $1.21(0.25)^{\ddagger}$ \\
\hline Medium & $0.11(0.18)$ & $0.12(0.30)$ & $-0.02(0.16)$ & $0.10(0.22)$ \\
\hline$\overline{R^{2}}$ & 0.633 & 0.497 & 0.660 & 0.562 \\
\hline$P$ & $<0.001$ & $<0.001$ & $<0.001$ & $<0.001$ \\
\hline \multirow[t]{2}{*}{ Model 2} & \multicolumn{4}{|c|}{ Access as number of shopping opportunities within 5 miles } \\
\hline & Fresh fruits & Overall fruits & Fresh vegetables & Overall vegetables \\
\hline Vehicle ownership & b (SE) & b (SE) & b (SE) & b (SE) \\
\hline Low & $0.47(0.25)$ & $1.05(0.38)^{\dagger}$ & $0.32(0.21)$ & $0.76(0.29)^{\dagger}$ \\
\hline Medium & $-0.03(0.24)$ & $0.28(0.38)$ & $0.07(0.21)$ & $0.11(0.29)$ \\
\hline$\overline{R^{2}}$ & 0.402 & 0.267 & 0.438 & 0.314 \\
\hline$P$ & $<0.001$ & $<0.001$ & $<0.001$ & $<0.001$ \\
\hline
\end{tabular}

NOTE: In models 1 and 2, the four equations were simultaneously estimated, controlling for population density. In model 1, deprivation entered as categorical variable; low deprivation is referent group. In model 2, vehicle ownership entered as categorical variable; high vehicle ownership is referent group. In both models, population density entered as continuous. Results are reported as multivariate-adjusted b (SE). Statistically significant variables are indicated as: ${ }^{*}<0.05$ ${ }^{\dagger}<0.01{ }^{\ddagger}<0.001$.

nutrient benefits of canned and frozen fruits and vegetables [69,71-77]. Our results show that, in this large rural area, the more disadvantaged neighborhoods had relatively better potential access to fresh fruits and vegetables and to combined fresh and processed fruits and vegetables than less disadvantaged neighborhoods. This suggests different processes operating in rural areas compared with large urban areas in U.S., many of which are socially and racially segregated.

Physical access to food stores has been shown to be a major problem for people in deprived communities; those without cars, older residents, people on low incomes, and residents of rural areas [36,47,48,53-57]. There may be challenges, even for those with relatively close potential access to healthy foods, due to the availability of a vehicle, lack of public transportation, limited financial resources (type, amount, timing, and competing demands), problems with the home environment (food storage, meal preparation area, and refrigeration), and the constraints of household size, and employment including location and work schedule. For example, limited household refrigeration may require a consumer to make frequent, costly trips for perishable food items; or purchase more expensive or less healthy food items from a retail store closer to home [14,30,31].

\section{Strengths}

There are several major methodological strengths to this study. First, this study relied on the identification of all traditional, convenience, and non-traditional food stores through ground truthing, a methodology that we have previously shown to be more accurate in small-town and rural areas than secondary or publicly acquired lists $[34,36]$. Second, we included multiple store types, such as convenience stores, dollar stores, and mass merchandisers, which reflect a more realistic picture of potential retail food opportunities. Finally, availability and variety of fruits and vegetables were determined through a comprehensive on-site observational survey that included fresh, canned, frozen, and 100\% juice forms of fruits and vegetables. This is in response to the criticism of others who posit that it is not enough to determine location of food stores in relation to neighborhoods without also considering the quality or healthiness of the food that is available $[17,21,61]$.

\section{Limitations}

Data allow us to examine potential spatial access, but do not capture purchase behavioral characteristics; that is, where and how frequently rural residents choose to shop for fruits and vegetables. An underlying assumption with most studies is that shopping trips originate from the residence; however, the starting point for food shopping may vary and depend on time and location of work or other activities in multiple stops that include food shopping $[17,106]$. Although we did not identify famer's markets or fruit/vegetable stands during our ground truthing, there was no measure of community or individual gardens. Future work with rural families will allow us to understand the role of non-retail sources for fruits or vegetables, such as food sharing, home gardens, and canning or freezing. The cost of collecting ground-based, comprehensive in-store data makes it difficult to replicate this study in numerous 
settings. However, we believe the value from the breadth and depth of data justifies the resources. Another limitation is the use of area-level data from the 2000 U.S. Census. We acknowledge that there have been changes since 2000; most notably, increased proportion of minority residents, greater unemployment, and increased proportion of low-income residents. We plan to update our work when data from the 2010 U.S. Census is released. Still, this is the best available source of CBGlevel data. Finally, we are limited in our ability to generalize beyond our rural region. However, the use of all store formats and forms of fruits and vegetables has relevance to an international audience. Future plans call for a similar examination in small-town and rural areas outside the U.S.

\section{Conclusion}

Despite these limitations, this study furthers our knowledge about access and availability of fruits and vegetables in retail food stores in a large rural area. This paper responded to the methodological challenges that have been identified in measuring potential access to food stores in rural areas [34]. The measurement of the food environment recognized the emergence of new and changing store formats. Supermarkets and grocery stores are no longer the only shopping opportunities for fruits or vegetables. Restricting shopping opportunities to supermarkets would understate the access to fruits or vegetables. Access was described in distance to the nearest food opportunity and cumulative opportunities or variety of opportunities within a specific geographic area [37]. Data on availability of fresh or processed fruits or vegetables in the measurements provide robust meaning to the concept of potential access in this large rural area. There remains an unanswered question. Do we think there are separate rural and urban definitions for access and availability? We posit that availability must include the target foods, such as fruits or vegetables. This is not a rural or urban construct; however, access as a distance measure does have different meanings. Although rural residents are more accustomed to travel than urban counterparts [17], vehicle ownership and time and resource costs must be included in a discussion of access. Future linking of utilization or realized access with potential access will enhance our understanding of access, as will a better understanding of individual or household travel patterns [107].

Access to a good variety of healthy foods, such as fruits and vegetables, can play a pivotal role in the nutritional health of rural families. Knowing more about the level of access to shopping opportunities for healthy foods is essential for combining environmental approaches with traditional health interventions to make it easier for individuals to make healthier food choices
[106]. This is highly relevant for an international audience. Small-town and rural settings are not small versions of urban areas. Access to an available source of healthy foods, such as fruits and vegetables requires the identification of policy and environmental strategies that adapt a food systems approach to rural settings and involve stakeholders that affect production and consumption. Supply-side interventions could include strategies to increase access to healthy foods through the development of alternative strategies for providing high quality foods. At the same time, efforts should expand the focus from supply and pricing to the ability of rural residents to access and afford. Future work calls for an examination of utilization of retail food stores, especially the degree to which families frequent and purchase food items from convenience and non-traditional food stores.

\section{Acknowledgements}

This research was supported in part by the National Center on Minority Health and Health Disparities grant \#5P20MD002295; and Centers for Disease Control and Prevention, Prevention Research Centers Program, through the Center for Community Health Development cooperative agreement \#5U48DP000045. The views are ours and do not represent those of the funders.

\section{Author details}

${ }^{1}$ Program for Research in Nutrition and Health Disparities, School of Rural Public Health, Texas A\&M Health Science Center, MS 1266, College Station, TX 77843-1266 USA. ${ }^{2}$ Center for Community Health Development, School of Rural Public Health, Texas A\&M Health Science Center, MS 1266, College Station, TX 77843-1266 USA. ${ }^{3}$ Program on GIS and Spatial Statistics, School of Rural Public Health, Texas A\&M Health Science Center, MS 1266, College Station, TX 77843-1266 USA.

\section{Authors' contributions}

JRS developed the original idea for the study. JRS worked on the development of the instrument and the protocol for collection of data. SAH conducted all geocoding and mapping. JRS wrote the first draft of the paper. JRS, SAH, and WRD read and approved the final manuscript.

\section{Competing interests}

The authors declare that they have no competing interests.

Received: 9 December 2009 Accepted: 25 May 2010 Published: 25 May 2010

\section{References}

1. U.S. Department of Health and Human Services and U.S. Department of Agriculture: Dietary Guidelines for Americans 2005. 2005 [http://www. health.gov/dietaryguidelines/dga2005/document/pdf/DGA2005.pdf], [cited 2005 January 14].

2. VanDuyn MA, Pivonka E: Overview of the health benefits of fruit and vegetable consumption for the dietetics professional: selected literature. J Am Diet Assoc 2000, 100:1511-21.

3. Ness AR, Powles JW: Fruit and vegetables, and cardiovascular disease: a review. Int J Epidemiol 1997, 26:1-13.

4. Steinmetz KA, Potter JD: Vegetables, fruit, and cancer prevention: a review. J Am Diet Assoc 1996, 96:1027-39.

5. Serdula MK, Byers T, Mokdad AH, Simoes E, Mendlein JM, Coates RJ: The association between fruit and vegetable intake and chronic disease risk factors. Epidemiology 1996, 7:161-5.

6. Joshipura KJ, Hu FB, Manson JE, Stampfer MJ, Rimm EB, Speizer FE, Colditz G, Ascherio A, Rosner B, Spiegelman D, Willett WC: The effect of fruit and vegetable intake on risk for coronary heart disease. Ann Intern Med 2001, 134:1106-14. 
7. Bazzano LA: The High Cost of Not Consuming Fruits and Vegetables. J Am Diet Assoc 2006, 106:1364-8.

8. Tohill BC, Seymour J, Serdula M, Kettel-Khan L, Rolls BJ: What Epidemiologic Studies Tell Us about the Relationship between Fruit and Vegetable Consumption and Body Weight. Nutrition Reviews 2004, 62:365-74.

9. Brand MK, Morris TF: More Efforts Needed to Better Understand Rural Public Health. J Public Health Management Practice 2009, 15:181-2.

10. Meit M: Bridging the Health Divide: The Rural Public Health Research Agenda. Bradford, PA: University of Pittsburgh Center for Rural Health Practice 2004.

11. Guenther PM, Dodd KW, Reedy J, Krebs-Smith SM: Most Americans Eat Much Less than Recommended Amounts of Fruits and Vegetables. J Am Diet Assoc 2006, 106:1371-9.

12. McClelland JW, Demark-Wahnefried W, Mustian RD, Cowan AT, Campbell MK: Fruit and vegetable consumption of rural African Americans: baseline survey results of the Black Churches United for Better Health 5 A Day Project. Nutr Cancer 1998, 30:148-57.

13. Carcaise-Edinboro P, McClish D, Kracen AC, Bowen D, Fries E: Fruit and Vegetable Dietary Behavior in Response to a Low-Intensity Dietary Intervention: The Rural Physician Cancer Prevention Project. Journal of Rural Health 2008, 24:299-305.

14. Shaw HJ: Food Deserts: Towards the Development of a Classification. Geogr Ann 2006, 88 B:231-47.

15. Zenk SN, Schulz AJ, Israel BA, James SA, Bao S, Wilson ML: Fruit and Vegetable Access Differs by Community Racial Composition and Socioeconomic Position in Detroit, Michigan. Ethn Dis 2006, 16:275-80

16. Morland K, Filomena S: Disparities in the availability of fruits and vegetables between racially segregated urban neighborhoods. Public Health Nutrition 2007, 10:1481-9.

17. U.S. Department of Agriculture Economic Research Service (ERS): Access to Affordable and Nutritious Food: Measuring and Understanding Food Deserts and Their Consequences. Report to Congress Washington, DC: USDA 2009

18. McLeroy KR, Bibeau D, Steckler A, Glanz K: An Ecological Perspective for Health Promotion Programs. Health Educ Q 1988, 15:351-78.

19. Egger G, Swinburn B: An "ecological" approach to the obesity pandemic. BMJ 1997, 315:477-80.

20. Story M, Kaphingst KM, Robinson-O'Brien R, Glanz K: Creating Healthy Food and Eating Environments: Policy and Environmental Approaches. Annu Rev Public Health 2008, 29:6.1-6.20.

21. Macintyre S: Deprivation amplification revisited; or, is it always true that poorer places have poorer access to resources for healthy diets and physical activity? International Journal of Behavioral Nutrition and Physical Activity 2007, 4:32

22. Brownson RC, Hagood L, Lovegreen SL, Britton B, Caito NM, Elliott MB, Emery J, Haire-Joshu D, Hicks D, Johnson B, McGill JB, Morton S, Rhodes G, Thurman T, Tune D: A multilevel ecological approach to promoting walking in rural communities. Preventive Medicine 2005, 41:837-42.

23. Glasgow R, Strycker LA, Toobert DJ, Eakin E: A Social-Ecological Approach to Assessing Support for Disease Self-Management: The Chronic Illness Resources Survey. Journal of Behavioral Medicine 2000, 23:559-83.

24. Morland K, Wing S, Roux AD: The Contextual Effect of the Local Food Environment on Residents' Diets: The Atherosclerosis Risk in Communities Study. Am J Public Health 2002, 92:1761-7.

25. Morland K, Wing S, Roux AD, Poole C: Neighborhood Characteristics Associated with the Location of Food Stores and Food Service Places. Am J Prev Med 2002, 22:23-9.

26. Furst T, Connors M, Bisogni CA, Sobal J, Falk LW: Food Choice: A Conceptual Model of the Process. Appetite 1996, 26:247-66.

27. Andreyeva T, Blumenthal DM, Schwartz MB, Long MW, Brownell KD: Availability and Prices of Foods Across Stores and Neighborhoods: The Case of New Haven, Connecticut. Health Affairs 2008, 27:1381-8.

28. Khan AA, Bhardwaj SM: Access to Health Care: A conceptual framework and its relevance to health care planning. Evaluation \& The Health Professions 1994, 17:60-76.

29. Guagliardo MF: Spatial accessibility of primary care: concepts, methods and challenges. International Journal of Health Geographics 2004, 3:3.

30. Turrell G, Hewitt B, Patterson C, Oldenburg B, Gould T: Socioeconomic differences in food purchasing behaviour and suggested implications for diet-related health promotion. J Hum Nutr Dietet 2002, 15:355-64.
31. Giskes K, vanLenthe FJ, Kamphuis CBM, Huisman M, Brug J, Mackenbach JP: Household and food shopping environments: do they play a role in socioeconomic inequalities in fruit and vegetable consumption? A multilevel study among Dutch adults. J Epidemiol Community Health 2009, 63:113-20.

32. Inagami S, Cohen DA, Finch BK, Asch SM: You Are Where You Shop: Grocery Store Locations, Weight, and Neighborhoods. Am J Prev Med 2006, 31:10-7.

33. Rose $D$, Richards $R$ : Food store access and household fruit and vegetable use among participants in the US Food Stamp Program. Public Health Nutrition 2004, 7:1081-8.

34. Sharkey JR: Measuring Potential Access to Food Stores and Food Service Places in Rural Areas in the United States. Am J Prev Med 2009, 36: S151-S5.

35. Satia JA: Diet-Related Disparities: Understanding the Problem and Accelerating Solutions. J Am Diet Assoc 2009, 109:610-5.

36. Sharkey J, Horel S: Neighborhood Socioeconomic Deprivation and Minority Composition Are Associated with Better Potential Spatial Access to the Food Environment in a Large Rural Area. J Nutr 2008, 138:620-7.

37. Apparicio P, Cloutier MS, Shearmur R: The case of Montreal's missing food deserts: Evaluation of accessibility to food supermarkets. International Journal of Health Geographics 2007, 6:4.

38. Zenk SN, Schulz AJ, Israel BA, James SA, Bao S, Wilson ML: Neighborhood Racial Composition, Neighborhood Poverty, and the Spatial Accessibility of Supermarkets in Metropolitan Detroit. Am J Public Health 2005, 95:660-7.

39. Larsen K, Gilliland J: Mapping the evolution of 'food deserts' in a Canadian city: Supermarket accessibility in London, Ontario, 1961-2005. International Journal of Health Geographics 2008, 7 .

40. Laraia BA, Siega-Riz AM, Kaufman JS, Jones SJ: Proximity of supermarkets is positively associated with diet quality index for pregnancy. Preventive Medicine 2004, 39:869-75

41. Dean WR, Sharkey JR: Rural and Urban Differences in the Associations between Characteristics of the Community Food Environment and Fruit and Vegetable Intake. Journal of Nutrition Education and Behavior 2010

42. Caldwell EM, Kobayashi MM, DuBow WM, Wytinck SM: Perceived access to fruits and vegetables associated with increased consumption. Public Health Nutrition 2008, 12(10):1743-50,

43. Robinson T: Applying the Socio-ecological Model to Improving Fruit and Vegetable Intake Among Low-Income African Americans. J Community Health 2008, 33:395-406.

44. Diez-Roux AV, Nieto FJ, Caulfied L, Tyroler HA, Watson RL, Szklo M: Neighbourhood differences in diet: the Atherosclerosis Risk in Communities (ARIC) Study. J Epidemiol Community Health 1999, 53:55-63.

45. Clarke G, Eyre H, Guy C: Deriving Indicators of Access to Food Retail Provision in British Cities: Studies of Cardiff, Leeds and Bradford. Urban Studies 2002, 39:2041-60

46. Wrigley N: 'Food Deserts' in British Cities: Policy Context and Research Priorities. Urban Studies 2002, 39:2029-40.

47. Clifton KJ: Mobility Strategies and Food Shopping for Low-Income Families. Journal of Planning Education and Research 2004, 23:402-13.

48. Shohaimi S, Welch A, Bingham S, Luben R, Day B, Wareham N, Khaw K-T: Residential area deprivation predicts fruit and vegetable consumption independently of individual educational level and occupational social class: a cross sectional population study in the Norfolk cohort of the European Prospective Investigation into Cancer (EPIC-Norfolk). J Epidemiol Community Health 2004, 58:686-91.

49. O'Dwyer LA, Coveney J: Scoping supermarket availability and accessibility by socio-economic status in Adelaide. Health Promotion Journal of Australia 2006, 17:240-6.

50. Pearson T, Russell J, Campbell MJ, Barker ME: Do 'food deserts' influence fruit and vegetable consumption? - a cross-sectional study. Appetite 2005, 45:195-7.

51. Cummins S, Petticrew M, Higgins C, Findlay A, Sparus L: Large-scale food retailing as a health intervention: quasi-experimental evaluation of a natural experiment. J Epidemiol Community Health 2005, 59:1035-40.

52. Wrigley N, Warm D, Margetts B: Deprivation, diet and food retail access: findings from the Leeds 'food deserts' study. Environ Plann A 2003, 35:151-88 
53. Powell LM, Slater S, Mirtcheva D, Bao Y, Chaloupka FJ: Food store availability and neighborhood characteristics in the United States. Preventive Medicine 2007, 44:189-95.

54. Larson NI, Story MT, Nelson MC: Neighborhood Environments: Disparities to Access to Healthy Foods in the US. Am J Prev Med 2009, 36:74-81.

55. Morton LW, Blanchard TC: Starved for Access: Life in Rural America's Food Deserts. Rural Realities 2007, 1:1-10.

56. Kaufman PR: Rural Poor Have Less Access to Supermarkets, Large grocery Stores. Rural Development Perspectives 1998, 13:19-26.

57. Liese $A D$, Weis $K E$, Pluto D: Food store types, availability and cost of foods in a rural environment. J Am Diet Assoc 2007, 107:1916-23.

58. Bustillos BD, Sharkey JR, Anding J, Mclntosh A: Availability of healthier food alternatives in traditional, convenience, and non-traditional types of food stores in two rural Texas counties. J Am Diet Assoc 2009, 109:883-9.

59. Smoyer-Tomic KE, Spence JC, Raine KD, Amrhein C, Cameron N, Yasenovskiy V, Cutumisu N, Hemphill E, Healy J: The association between neighborhood socioeconomic status and exposure to supermarkets and fast food outlets. Health \& Place 2008, 14:740-54

60. Smoyer-Tomic KE, Spence JC, Amrhein C: Food Deserts in the Prairies? supermarket Accessibility and Neighborhood Need in Edmonton, Canada. The Professional Geographer 2006, 58:307-26.

61. Macdonald L, Ellaway A, Macintyre S: The food retail environment and area deprivation in Glasgow City, UK. International Journal of Behavioral Nutrition and Physical Activity 2009, 6:52

62. Kaufman PR: Nontraditional Retailers Are Challenging Traditional Grocery Stores. Food Marketing 1998, 31-3.

63. Martinez S, Kaufman P: Twenty Years of Competition Reshape the U.S. Food Marketing System. AmberWaves 2008, 6:29-35.

64. Leibtag E: The Impact of Big-Box Stores on Retail Food Prices and the Consumer Price Index. USDA ERS Economic Research report Number 33 2006.

65. Hale T: Dollar Store, No Frills: The New Retail Landscape. Consumer Insight 2004, Spring 2004:11-3, 42

66. Blanchard T, Lyson T: Access to Low Cost Groceries in Nonmetropolitan Counties: Large Retailers and the Creation of Food Deserts. [http://srdc. msstate.edu/measuring/blanchard.pdf], [cited May 12, 2005].

67. Martens BJ: An Analysis of the Retail Grocery Industry: The Spatial Effects of Supercenters. West Lafayette Purdue University 2006.

68. Artz GM, Stone KE: Analyzing the Impact of Wal-Mart Supercenters on Local Food Store Sales. 2006 [http://www.entrepreneur.com/tradejournals/ article/156054929_2.html], [cited December 2006].

69. Klein B, Kaletz R: A Study of Canned Food Nutrition. 1997 [http://nutrican. fshn.uiuc.edu/home.html], [cited 2010 March 24].

70. USDA Center for Nutrition policy and Promotion (CNPP): MyPyramid. 2008 [http://www.mypyramid.gov/], [cited 2008 March 24]

71. Winkler $E$, Turrell G, Patterson C: Does living in a disadvantaged area mean fewer opportunities to purchase fresh fruit and vegetables in the area? Findings from the Brisbane food study. Health \& Place 2006, 12:741-8.

72. Franco M, Roux AVD, Glass TA, Caballero B, Brancati FL: Neighborhood Characteristics and Availability of Healthy Foods in Baltimore. Am J Prev Med 2008, 35:561-7.

73. Hosler A, Rajulu DT, Frederick BL, Ronsani AE: Assessing Retail Fruit and Vegetable Availability in urban and Rural Underserved Communities. Prev Chronic Dis 2008, 5.

74. Rickman JC, Barrett DM, Bruhn CM: Nutritional comparison of fresh, frozen and canned fruits and vegetables. Part 1. Vitamins $C$ and $B$ and phenolic compounds. J Sci Food Agric 2007, 87:930-44.

75. Algert SJ, Agrawal A, Lewis DS: Disparities in Access to Fresh Produce in Low-Income Neighborhoods in Los Angeles. Am J Prev Med 2006, 30:365-70

76. Guthrie JF, Morton JF: Food sources of added sweeteners in the diets of Americans. J Am Diet Assoc 2000, 100:43-8, 51.

77. Cotton PA, Subar AF, Friday JE: Dietary Sources of Nutrients among US Adults, 1994 to 1996. J Am Diet Assoc 2004, 104:921-30.

78. Travers K, Cogdon A, McDonald W, Wright C, Anderson B, MacLean D: Availability and cost of heart healthy dietary changes in Nova Scotia. J Can Diet Assoc 1997, 58:176-83.

79. Lee AJ, Darcy AM, Leonard D, Groos AD, Stubbs CO, Lowson SK, Dunn SM, Coyne T, Riley MD: Food availability, cost disparity and improvement in relation to accessibility and remoteness in Queensland. Aus N Z J Public Health 2002, 26:266-72.

80. Strong DA, Grosso PD, Burwick A, Jethwani V, Ponza M: Rural Research Needs and Data Sources for Selected Human Services Topics. Research Needs Princeton, NJ: Mathematica Policy Research, Inc 2005, 1.

81. US Census Bureau: Geographic Areas Reference Manual. [http://www. census.gov/geo/www/garm.html], [cited November 18, 2006].

82. U.S. Census Bureau: State and County QuickFacts. [http://quickfacts.census. gov/qfd/states/48/48215.html], [cited February 18, 2007].

83. U.S. Census Bureau: [http://www.census.gov], [cited].

84. Brazos Transit District: Brazos Transit District. [http://www.btd.org/], [cited 8/10/2007].

85. Brazos Valley Council of Governments: "Here to There" Coordinated Regional Public Transportation Plan, Brazos Valley Region, Texas. 2006.

86. Winkleby M, Cubbin C, Ahn D: Effect of Cross-Level Interaction Between Individual and Neighborhood Socioeconomic Status on Adult Mortality Rates. Am J Public Health 2006, 96:2145-53.

87. Hanigan I, Hall G, Dear KB: A comparison of methods for calculating population exposure estimates of daily weather for health research. International Journal of Health Geographics 2006, 5.

88. Smoyer-Tomic KE, Hewko JN, Hodgson MJ: Spatial accessibility and equity of playgrounds in Edmonton, Canada. The Canadian Geographer 2004, 48:287-302.

89. Cuzick J: A Wilcoxon-type test for trend. Statistics in Medicine 1985 4:87-90.

90. Nielsen Company: High and Middle Income Shoppers Spending More in Dollar Stores. 2009 [http://blog.nielsen.com/nielsenwire/consumer/ high-and-middle-income-shoppers-spending-more-in-dollar-stores/], [cited 2010 March 27].

91. Tosh M: Retail lines lose definition - Special Report: Channel Blurring drug store industry analysis. 2002 [http://findarticles.com/p/articles/ mi_m3374/is_6_24/ai_85285889/print], [cited 2008 April 1].

92. Leibtag ES: Where You Shop Matters: Store Formats Drive Variation in Retail Food Prices. AmberWaves 2005, 2005:13-8.

93. Shih W, Kaufman S, McKillican R: Dollar General (A). 2007 [http://www. hbsp.harvard.edu], [cited 2008 April 18]; 9-607-140:[Case Study].

94. Blanchard T, Lyson T: Food Availability \& Food Deserts in the Nonmetropolitan South. 2006, 2006 [http://srdc.msstate.edu/focusareas/ health/fa/fa_12_blanchard.pdf], [cited 2007 August 5].

95. Cummins S, Macintyre S: "Food deserts"-evidence and assumption in health policy making. BMJ 2002, 325:436-8.

96. Blanchard TC, Matthews TL: Retail Concentration, Food Deserts, and Food-Disadvantaged Communities in Rural America. Remaking the North America Food System Lincoln, NE: University of Nebraska PressHinrichs CC, Lyson TA 2007, 201-15.

97. Alwitt LF, Donley TD: Retail Stores in Poor urban Neighborhoods. The Journal of Consumer Affairs 1997, 31:139-64.

98. Moore LV, Diez Roux AV: Association of Neighborhood Characteristics With the Location and Type of Food Stores. Am J Public Health 2006, 96:325-31.

99. Baker EA, Schootman M, Barnidge E, Kelly C: The Role of Race and Poverty in Access to Foods That Enable Individuals to Adhere to Dietary Guidelines. Preventing Chronic Disease 2006, 3:A76.

100. Block D, Kouba J: A comparison of the availability and affordability of a market basket in two communities in the Chicago area. Public Health Nutrition 2006, 9:837-45.

101. Raja S, Ma C, Yadav P: Beyond Food Deserts: Measuring and Mapping Racial Disparities in Neighborhood Food Environments. Journal of Planning Education and Research 2008, 27:469-82.

102. Ball K, Timperio A, Crawford D: Neighbourhood socioeconomic inequalities in food access and affordability. Health \& Place 2009, 15:578-85

103. Latham J, Moffat T: Determinants of variation in food cost and availability in two socioeconomically contrasting neighborhoods of Hamilton, Ontario, Canada. Health \& Place 2007, 13:273-87.

104. Pearce J, Hiscock R, Blakely T, Witten K: The contextual effects of neighbourhood access to supermarkets and convenience stores on individual fruit and vegetable consumption. J Epidemiol Community Health 2008, 62:198-201. 
105. Pearce J, Blakely T, Witten K, Bartie P: Neighborhood Deprivation and Access to Fast-Food Retailing: A National Study. Am J Prev Med 2007, 32:375-82.

106. Seymour JD, Yaroch AL, Serdula M, Blanck HM, Khan LK: Impact of nutrition environmental interventions on point-of-purchase behavior in adults: a review. Preventive Medicine 2004, 39:S108-S36.

107. Bureau of Labor Statistics and U.S. Census Bureau: American Time Use Survey Questionnaire. [http://www.bls.gov/tus/tuquestionnaire.pdf], [cited 5/2/07].

108. Sharkey JR, Horel S, Han D, Huber JC: Association between Neighborhood Need and Spatial Access to Food Stores and Fast Food Restaurants in Neighborhoods of Colonias. Int I Health Geogr 2009, 8:9.

doi:10.1186/1476-072X-9-26

Cite this article as: Sharkey et al:: Neighborhood deprivation, vehicle ownership, and potential spatial access to a variety of fruits and vegetables in a large rural area in Texas. International Journal of Health Geographics 2010 9:26.

\section{Submit your next manuscript to BioMed Central} and take full advantage of:

- Convenient online submission

- Thorough peer review

- No space constraints or color figure charges

- Immediate publication on acceptance

- Inclusion in PubMed, CAS, Scopus and Google Scholar

- Research which is freely available for redistribution

Submit your manuscript at www.biomedcentral.com/submit
C Biomed Central 